\title{
Remote response of the Indian Ocean to interannual SST variations in the tropical Pacific
}

\author{
Toshiaki Shinoda, Michael A. Alexander \\ NOAA-CIRES Climate Diagnostics Center \\ 325 Broadway \\ Boulder, CO 80303 \\ email: Toshiaki.Shinoda@noaa.gov
}

\author{
Harry H. Hendon \\ Bureau of Meteorology Research Centre \\ PO Box 1289K, Melbourne 3001, AUSTRALIA
}

revised

July 29, 2003 


\section{Abstract}

Remote forcing of sea surface temperature (SST) variations in the Indian Ocean during the course of El Nino/Southern Oscillation (ENSO) events is investigated using NCEP reanalysis and general circulation model (GCM) experiments. Three experiments are conducted to elucidate how SST variations in the equatorial Pacific influence surface flux variations, and hence SST variations, across the Indian Ocean. A control experiment is conducted by prescribing observed SSTs globally for the period 1950-99. In the second experiment, observed SSTs are prescribed only in the tropical eastern Pacific, while climatological SSTs are used elsewhere over the global oceans. In the third experiment, observed SSTs are prescribed in the tropical eastern Pacific, while a variable-depth ocean mixed layer model is used at all other ocean grid points to predict the SST.

Composites of surface fluxes and SST over the Indian Ocean are formed based on El Nino and La Nina events during 1950-1999. The surface flux variations in the eastern Indian Ocean in all three experiments are similar and realistic, confirming that much of the surface flux variation during ENSO is remotely forced from the Pacific. Furthermore, the SST anomalies in the eastern tropical Indian Ocean are well simulated by the coupled model, which supports the notion of an "atmospheric bridge" from the Pacific. During boreal summer and fall, when climatological winds are southeasterly over the eastern Indian Ocean, remotely forced anomalous easterlies act to increase the local wind speed. SST cools in response to increased evaporative cooling, which is partially offset by increased solar radiation associated with reduced rainfall. During winter, the climatological winds become northwesterly and the anomalous easterlies then act to reduce the wind speed and evaporative cooling. Together with increased solar radiation and a shoaling mixed layer, the SST 
warms rapidly. The model is less successful at reproducing the ENSO-induced SST anomalies in the western Indian Ocean, suggesting that dynamical ocean processes contribute to the east-west SST dipole that is often observed in boreal fall during ENSO events. 


\section{Introduction}

An important attribute of El Nino-Southern Oscillation (ENSO) is that it drives changes in the global atmospheric circulation. ENSO- induced anomalies over the land masses surrounding the Indian Ocean include reduced rainfall in the Indian summer monsoon, reduced rainfall in the late dry season (August-October) in Indonesia, and enhanced rainfall during the wet season (November-January) in eastern Africa (e.g., Roplewski and Halpert 1987, Kiladis and Diaz 1989). There is growing evidence that these rainfall anomalies are driven both by remotely forced circulation changes from the equatorial Pacific and by sea surface temperature (SST) anomalies in the Indian Ocean (e.g. Hastenrath et al. 1993; Goddard and Graham 1999; Lau and Nath 2000; Rowell 2001). While typical SST anomalies in the Indian Ocean during ENSO are only $1 / 2$ to $1 / 3$ as large as those in the equatorial central and eastern Pacific, the high mean temperatures in the former imply that small SST changes can drive significant rainfall and circulation anomalies (e.g., Palmer and Mansfield 1984).

It is difficult to attribute the cause of observed rainfall anomalies during ENSO to SSTs in a particular region, since SST anomalies in the Indian Ocean co-evolve with those in the Pacific. The typical evolution during the ENSO cycle (e.g., Rassmusson and Carpenter 1982) are for cold anomalies to develop in the equatorial eastern Indian Ocean/Indonesian region when warm anomalies are becoming prominent in the equatorial central Pacific (June-July). The western Indian Ocean then begins to warm and by boreal autumn, as warm anomalies begin to peak in the central Pacific, an anomalously negative zonal gradient of SST across the equatorial Indian Ocean develops (Baquero-Bernal et al. 2002). At the peak phase of ENSO in the Pacific (Dec-Jan), the western Indian Ocean continues to warm and the cold SST anomalies in the eastern Indian Ocean rapidly decay and even change sign (Nicholls 1981). The 
resultant basin-scale warming in the Indian Ocean typically peaks some 3-4 months after the peak warming in the central Pacific (Klein et al. 1999).

The ENSO-related rainfall anomalies during the eastern African wet season (DecemberMarch) have been attributed to the basin-scale warming that is typically evident by December during a warm event (e.g., Goddard and Graham 1999). On the other hand, the most dramatic rainfall impacts in the eastern Indian Ocean/Indonesian region occur during boreal autumn (e.g., Flohn 1986; Hendon 2002), when the anomalous zonal SST gradient in the Indian Ocean is most developed. The strong negative correlation of Indonesian rainfall with ENSO tends to disappear after SSTs warm in the eastern Indian Ocean in late boreal autumn.

The mechanism for generation of the SST anomalies in the Indian Ocean that develop in conjunction with ENSO is unclear. The eastward shift of the Walker circulation results in anomalous surface easterlies and reduced cloud cover over the equatorial eastern Indian and far western Pacific Oceans (e.g., Rassmusson and Carpenter 1982). These wind and cloud cover changes impact the latent heat flux, surface short wave radiation and wind stress. Klein et al. (1999) and Venzke et al (2000) argue that the basin-scale warming of the Indian Ocean primarily results from a combination of reduced latent heat flux, associated with anomalous easterlies, and increased short wave radiation, stemming from the reduction in cloud cover. Hendon (2002) argues further that the negative SST anomalies that develop in the eastern Indian Ocean during boreal autumn and their rapid demise once the Australian summer monsoon commences in early boreal winter can be accounted for by changes in the surface heat flux. The same easterly anomalies, which reduce the surface wind speed during December-March, increase the wind speed in the Indonesian region during August-November (e.g., Hackert and Hastenrath 1986). Hence, the easterly anomalies initially act to cool the eastern Indian Ocean and work against the warming 
associated with increased short wave radiation produced by reduced cloud cover.

The same easterly anomalies also drive a dynamical response in the Indian Ocean, whereby the equatorial thermocline is elevated in the east and suppressed in the west, and upwelling is promoted off the west coast of the Indonesian archipelago (e.g., Chambers et al. 1999; Murtugudde and Bussalacchi 1999). Together, these dynamical mechanisms will act to warm (cool) the western (eastern) equatorial Indian Ocean. These dynamical mechanisms appear to be especially important during late 1997 (e.g., Murtugudde et al 2000), when SST anomalies at opposite sides of the Indian Ocean exceeded $2^{\circ} \mathrm{C}$ reversing the mean zonal SST gradient (e.g., Yu and Rienecker 1999).

Out-of-phase SST anomalies across the Indian Ocean, together with drought in Indonesia and floods in eastern Africa, occasionally develop during boreal autumn in the absence of well defined ENSO events in the Pacific, such as occurred in 1961 (Reverdin et al. 1986; Flohn 1987). Coupled air-sea dynamics in the Indian Ocean appear to explain this interannual variability (e.g., Reverdin et al. 1986; Saji et al. 1999; Webster et al. 1999). Forced ocean model experiments and coupled GCMs, however, suggest that, while coupled behavior exists with some degree of independence from ENSO, remote forcing by ENSO in the Pacific provides the main excitation of the zonally out-of-phase behavior (e.g., Murtugudde et al 2000; Baquero-Bernal et al. 2002).

While many questions remain with regard to the dynamics of interannual variability in the Indian Ocean, here we will focus on the generation of SST anomalies by surface heat flux variations and mixed layer processes remotely forced from the Pacific. Previously Lau and Nath (2003) focused on the basin-wide warming during boreal winter and spring associated with ENSO using an AGCM coupled to an ocean mixed layer model. Observed SSTs were prescribed in the central and east- 
ern tropical Pacific Ocean and the ocean mixed layer model was used to predict the SST elsewhere. Their results indicate that SST variations in the central and eastern Pacific associated with ENSO can perturb the Walker circulation, and that observed SST anomalies in the Indian-western Pacific Oceans several months after the peak in ENSO can be developed by the anomalous surface atmospheric circulation.

Using a similar experimental design as in Lau and Nath (2003), we will focus on the seasonal evolution of SST anomalies in the Indian Ocean that can be driven by surface heat flux variations remotely forced from the Pacific. In particular, we will focus on the seasonality of the development of the anomalous zonal SST gradient in the Indian Ocean, which, during ENSO tends to peak in boreal autumn and then rapidly decay, giving way to basin-scale warming. We will also look at other mixed layer processes, such as variations in the mixed later depth, entrainment heat flux and penetrative shortwave radiation.

This paper is organized as follows: The models and experimental design are described in section 2. In section 3, ENSO-based composite surface heat flux variations from the model are compared to observations. The evolution of the remotely forced SST variations are discussed in Sec. 4. Finally, conclusions are provided in section 5. 


\section{Experiment Design}

\subsection{Model Experiments}

Three sets of GCM experiments with different ocean configurations were conducted to elucidate how SST variations in the tropical Pacific may influence air-sea fluxes, and hence, SSTs in the Indian Ocean. In the first experiment, SSTs at all ocean grid points between $60^{\circ} \mathrm{N}$ and $40^{\circ} \mathrm{S}$ were prescribed to evolve according to observations (Smith et al. 1996) for the period 1950-1999. Climatological SSTs were specified over the remainder of the oceans. An ensemble of 4 integrations were conducted with slightly different initial conditions taken from a control run. These simulations, referred to as global ocean-global atmosphere (GOGA) runs, are used to infer how the surface fluxes evolve over the Indian Ocean given "perfect" boundary conditions.

The second experiment used the same observed SSTs in the tropical eastern and central Pacific $\left(15^{\circ} \mathrm{S}-15^{\circ} \mathrm{N}, 172^{\circ} \mathrm{E}-\right.$ South American coast), but with climatological SSTs specified over the remainder of the world's oceans. An ensemble of 8 integrations were performed. These eastern/central Pacific ocean-global atmosphere (EPOGA) runs were designed to determine how much of the surface heat flux anomalies produced in the GOGA run are driven by remote SST variations in the tropical eastern and central Pacific, in particular those variations associated with ENSO. Zonal shifts of convective activity during ENSO events are not largely affected by the zonal SST gradient at the artificial boundary at $172^{\circ} \mathrm{E}$ (not shown).

The third experiment is similar to the EPOGA configuration except that a onedimensional mixed layer ocean model was coupled to the atmospheric model at each grid point outside of the tropical east Pacific. The ocean model simulates the mixed layer temperature, equivalent to the SST, while in the eastern and central tropical Pacific SSTs were prescribed as in the EPOGA experiment. An ensemble of 16 integra- 
tions were performed. These mixed layer model (MLM) runs explicitly demonstrate how SST anomalies in the Indian Ocean can be remotely driven by SST variations in the eastern and central Pacific. They also allow for local air-sea feedback, which we find to be modest and will be presented in a later study.

\subsection{Atmosphere and Ocean Models}

The experiments were performed with an atmospheric GCM developed at the Geophysical Fluid Dynamics Laboratory (GFDL). The model has 14 sigma levels in the vertical and is truncated rhomboidally at wavenumber 30 . The physical grid, where for instance surface fluxes are computed, has horizontal resolution of approximately $2.25^{\circ}$ latitude by $3.75^{\circ}$ longitude. Detailed description of the model physics is found in Manabe and Hahn (1981), Lau (1981) and Gordon and Stern (1982). Many features of the model's climate are described in Alexander and Scott (1997). Lau and Nath (2000) discuss in detail the ability of the model to simulate interannual variability of the Asian and Australian summer monsoons.

The one-dimensional ocean mixed layer model used in the MLM experiments consists of a bulk mixed layer atop a layered model extending down to $1000 \mathrm{~m}$ or to the ocean bottom, whichever is shallower. The model and coupling procedure are described in detail in Alexander et al. (2000, 2002). The bulk model is based on the formulation of Gaspar (1988) and simulates the mixed layer depth, temperature and salinity. It responds to air-sea fluxes of heat, momentum and freshwater. It accounts for penetrative short wave radiation, and turbulent entrainment into the mixed layer, but not horizontal and vertical advective processes. Beneath the bulk mixed layer, heat is redistributed via vertical diffusion and convective adjustment. There are 31 levels from the surface to $1000 \mathrm{~m}$ with 15 layers in the upper $100 \mathrm{~m}$. All layers completely within the mixed layer are set to the bulk model values. The flux 
adjustment, described in Alexander et al. (2000), guarantees a stable and realistic seasonally varying mean state. The magnitude of the flux correction is $10-25 \mathrm{~W} / \mathrm{m}^{2}$ over most of the tropical Indian Ocean. The net surface heat flux in the subsequent sections includes the flux adjustment. Note that the ENSO composite of surface the heat fluxes are not affected by the flux correction since the correction values are exactly the same during warm events and cold events. 


\section{ENSO composite of SST and surface fluxes}

In this section, we develop an ENSO-based composite evolution of observed SSTs and surface heat fluxes based on NCEP reanalyses (Kalnay et al. 1996) and from the GOGA experiment to examine the realism of surface heat fluxes produced by the model when given "perfect" boundary conditions.

Composites are formed based on 9 El Nino events (1957, 1965, 1969, 1972, 1976, 1982, 1987, 1991, 1997) and 9 La Nina events $(1950,1954,1955,1964,1970,1973$, 1975, 1988, 1998). The first 8 El Nino and La Nina events were identified by Lau and Nath (2000) based on the monthly SST anomaly in the $5^{\circ} \mathrm{S}-5^{\circ} \mathrm{N}, 120-150^{\circ} \mathrm{W}$ region, to which we have added the $1997 \mathrm{El}$ Nino and 1998 La Nina events. We refer these years as Year(0), and the following years as Year(1). Over the Indian Ocean composite El Nino anomalies are nearly but not exactly opposite to the La Nina anomalies (e.g., Baquero-Bernal et al. 2002). However, we will treat them as opposites and form composites based on El Nino years minus La Nina years (also referred to as

warm-cold in the subsequent figures). For both model and observations, composites are formed from anomalies that were created by subtracting the respective mean seasonal cycles.

For reference, the composite evolution of Nino3.4 SST (observed SST averaged $5^{\circ} \mathrm{N}-5^{\circ} \mathrm{S}, 120^{\circ} \mathrm{E}-170^{\circ} \mathrm{W}$ ) is shown in Fig. 1. Nino3.4 SST peaks in early boreal winter and then declines through spring. The associated evolution of SST across the equatorial Indian Ocean (averaged $10^{\circ} \mathrm{N}$ and $10^{\circ} \mathrm{S}$ ) is displayed in Fig. 2a. In the eastern Indian Ocean, a cold anomaly is evident as early as June (0). It peaks around September (0). By this time, a warm anomaly in the western Indian Ocean has developed, giving rise to an anomalously negative zonal SST gradient that peaks in about October (0). The eastern Indian Ocean then warms rapidly (e.g., Nicholls 1984), yielding 
a basin-scale warm anomaly by Dec (0). At these latitudes, the basin-scale warm anomaly peaks around January (1), which is when the ENSO-related SST anomaly in the central Pacific tends to peak (Fig. 1). This basin-scale warming peaks somewhat earlier than indicated by Klein et al (1999), which is possibly due to the near equatorial averaging used here. This result is also consistent with the analysis by Xie et al. (2002).

The ENSO signal in the Indian Ocean has traditionally been described as a basinscale warming that lags the peak warming in the central Pacific by a few months (e.g., Klein et al. 1999). Baquero-Bernal et al. (2002) emphasized that the development of the "dipole" structure in boreal autumn is part of the evolving signal of ENSO in the Indian Ocean, but is only evident if seasonally stratified data are considered. By late boreal autumn, the eastern Indian Ocean tends to warm rapidly during El Nino, causing the "dipole" structure to give way to the basin-scale mode.

The horizontal structure of the SST anomalies in boreal autumn, when the anomalous zonal gradient is most pronounced, is displayed in Fig. 2b. The cold anomaly in the eastern Indian Ocean exceeds $0.5^{\circ} \mathrm{C}$ and is centered south of Sumatra around $110^{\circ} \mathrm{E}-120^{\circ} \mathrm{E}$. The warm anomaly (magnitude $0.5-0.8^{\circ} \mathrm{C}$ ) is centered near $60^{\circ} \mathrm{E}$ between $10^{\circ} \mathrm{N}-10^{\circ} \mathrm{S}$. The magnitude and spatial structure of these SST anomalies are consistent with the ENSO composite developed by Baquero-Bernal et al. (2002), who used a different data set and slightly different years. The anomalous zonal gradient during boreal autumn is also found by using seasonally-stratified correlations with the Southern Oscillation (Hastenrath et al. 1993). This structure is also similar to the zonal "dipole" described by Saji et al. (1999) and Webster et al. (1999).

The association of this anomalous zonal SST gradient with ENSO during boreal autumn is further explored using empirical orthogonal function (EOF) analysis of SST in the Indian Ocean basin. The EOFs are computed for the September-November 
mean SST anomalies in the domain $\left(30^{\circ} \mathrm{E}-130^{\circ} \mathrm{E}, 25^{\circ} \mathrm{N}-25^{\circ} \mathrm{S}\right)$. The leading EOF (Fig. 3a) captures $43.2 \%$ of the variance and its spatial structure is similar to the ENSO composite for this season (Fig. 2b). Its time variation is displayed in Fig. 3b along with the time series of Nino3.4 SST. The zero-lag correlation between the two is 0.61 , which implies a strong connection between the occurrence of the "dipole" and ENSO conditions in the Pacific (see also Hastenrath et al. 1993 and Hendon 2002). The forced ocean GCM runs of Murtugudde and Bussalacchi (1999) and Murtugudde et al. (2000) further support this premise. EOF 1 occasionally has large amplitude when Nino3.4 is quiescent (e.g. 1961), but this appears to be the exception rather than the rule. Nonetheless, the possibility exists that coupled air-sea dynamics within the Indian Ocean can produce out-of-phase behavior during boreal autumn in the absence of ENSO (e.g., Reverdin et al. 1986; Saji et al. 1999; Webster et al. 1999). Note that the correlation coefficient of PC-1 with the Nino3.4 SST during June-August (JJA) is almost same (0.61) as that with the SON Nino3.4 SST.

\subsection{Composite surface fluxes}

The possible role that surface heat flux variations may have in driving the observed ENSO-related SST variations in the Indian Ocean is now addressed. We will focus on the development of both the anomalous zonal gradient (the "dipole"), which peaks in boreal autumn, and the basin-scale anomaly, which peaks in the following boreal winter. The relationship between SST and surface heat flux variations is examined in detail for the tropical eastern Indian Ocean $\left(100^{\circ} \mathrm{E}-120^{\circ} \mathrm{E}, 5^{\circ} \mathrm{S}-15^{\circ} \mathrm{S}\right)$ and for the tropical western Indian Ocean $\left(50^{\circ} \mathrm{E}-60^{\circ} \mathrm{E}, 10^{\circ} \mathrm{N}-10^{\circ} \mathrm{S}\right)$. For reference, the composite SST anomalies in these two boxes are shown in Fig. 1. Consistent with the discussion

of Fig. 2, the anomalous zonal gradient is seen to peak in October (0), followed by rapid warming in the eastern box, yielding a zonally in-phase warm anomaly beginning 
in December $(0)$.

The net surface heat flux composites from NCEP reanalysis and the ensemble mean of the GOGA experiments are shown for the eastern and western boxes in Fig. 4. Note that positive surface heat fluxes always indicate heating of the ocean in the subsequent figures. In the eastern box, the surface heat flux from the GOGA experiments and NCEP reanalysis show similar cooling during boreal summer and fall and subsequent warming during winter. The heat flux leads the SST variation, consistent with the notion that the SST variation is being driven by the heat flux. Hendon (2002) argues that the magnitude of the surface heat flux is sufficient to drive the observed SST variation, assuming the heat is deposited into a mixed layer of typical depth (25-40 m, e.g., Monterey and Levitus 1997).

The heat flux variation in the western Indian Ocean is much smaller, and the flux variations from the GOGA experiment and NCEP reanalysis are dissimilar. Furthermore, there appears to be little correspondence between the heat flux and observed SST variations, suggesting that the SST variation during ENSO in the western Indian Ocean may not be primarily controlled by the surface heat. Previous studies also suggest that SSTs in the western Indian Ocean are strongly affected by ocean dynamics (e.g., Rao and Sivakumar 2000, McCreary et al. 1993, Schott and McCreary 2001).

The two dominant terms of the surface heat flux variation are latent heat flux and net short wave radiation (Fig. 5). In the eastern box, both the model and observations indicate that the cooling in boreal summer and autumn stems from enhanced upward latent heat flux (increased evaporative cooling), which initially dominates over increased short wave radiation. The subsequent warming in late autumn and into winter results from decreased latent heat flux (reduced evaporative cooling) in conjunction with increased short wave radiation (see also Hackert and Hastenrath 1986 and Hendon 2002). While latent heat flux from the model agrees 
fairly well with observations, the agreement of short wave radiation is not as good as the latent heat flux. This is probably due to the model deficiency to simulate convective anomalies.

In the paradigm of the atmospheric bridge (e.g., Klein et al. 1999), the anomalous latent heat flux and short wave radiation are driven by an eastward shift of the Walker circulation, which results in anomalous easterlies and reduced rainfall over the eastern Indian Ocean (Fig. 6). The easterlies are associated with increased latent heat flux in the summer and fall and reduced latent heat flux in winter (Fig. 5). This change in sign of the latent heat flux, while the zonal wind anomaly retains the same sign, reflects the monsoonal circulation in this region (discussed in detail below). Decreased rainfall, beginning in boreal summer and peaking in autumn (Fig. 6), is associated with decreased cloudiness and results in increased short wave radiation (Fig. 5). The evolution of zonal wind and rainfall from GOGA agrees reasonably well with observed, however the anomalies in the model are weaker than observations, especially in November and December. Note that the spread of composite precipitation is 0.1$0.2 \mathrm{~cm} /$ day, and all ensemble members underestimate negative precipitation anomaly during this period. Despite the weaker surface wind anomaly, the latent heat flux in the model does not show a corresponding deficiency. The weaker surface wind anomalies in late autumn in the model would be expected to have a deleterious impact on any dynamical response in the ocean, which could affect the SST evolution if and where advective processes are important (see further discussion in Sec. 5). 


\section{Remotely forced surface fluxes and SST}

In the previous section, we demonstrated that the atmospheric model can generate the observed surface flux variations across the Indian Ocean (more so in the east than in the west) during ENSO, given "perfect" boundary forcing. In this section, we examine how much of this surface flux variation can be generated by remote forcing from the Pacific, and whether these flux variations are adequate to generate realistic SST anomalies in the Indian Ocean.

The evolution of the surface flux anomalies in the eastern Indian Ocean is similar in the three model experiments (Fig. 7) with oceanic cooling in July-October, followed by warming which persists through the following winter. The amplitude and phasing of the SST variation from the MLM run (Fig. 7) also agrees well with observations (Fig. 4a), suggesting that the observed ENSO-induced SST variations in the eastern Indian Ocean are driven by surface flux anomalies associated with the atmospheric bridge.

The initial surface cooling during boreal summer in the model experiments and in observations (see Fig. 5) are predominantly due to increased latent heat flux, while the subsequent warming in late autumn/early winter results from a combination of reduced latent heat flux and increased short wave radiation (not shown). The latent heat flux variations are primarily caused by wind speed anomalies, which are similar in all three runs (Fig. 8). During boreal summer and fall, the wind speed is greater than normal in all three experiments, producing anomalous evaporative cooling, while the reverse occurs in winter. The wind speed anomalies reverse sign over the ENSO cycle even though the anomalous zonal winds are always easterly (Fig. 9a and also Fig. 6a). This is due to the interaction between the annual cycle of local winds and the anomalous winds associated with ENSO. The easterly anomalies over the 
eastern Indian Ocean are maintained by the eastward shift of the Walker circulation (e.g. Hendon 2002). During boreal summer and fall the climatological winds are easterly (Fig. 9b) and thus the remotely forced anomalous easterlies enhance the wind speed. During winter, the climatological winds, associated with Australian summer monsoon, become westerly and so the remotely forced easterly anomaly reduces the wind speed. Thus, the rapid development of the Australian summer monsoon is vital to the seasonality of the SST anomalies in the eastern Indian Ocean during ENSO.

Annual and interannual wind speed fluctuations also impact the mixed layer depth (MLD), which affects the sensitivity of the SST to surface heat flux forcing (e.g., Alexander et al. 2000; Lau and Nath 2003). The MLD in the eastern Indian Ocean in the MLM run varies from $\sim 70 \mathrm{~m}$ in boreal summer to $\sim 20 \mathrm{~m}$ in winter (Fig. 10a), which is consistent with observations (e.g., Monterey and Levitus 1997). Climatologically, mixed layer is deepest in boreal summer when the mean easterlies are the strongest and shallowest in boreal winter when the monsoonal westerlies are relatively weak. The MLD also varies over the course of the ENSO cycle in association with the wind speed anomalies discussed above. During boreal summer, when easterly anomalies enhance the total wind speed, the mixed layer is anomalously deep, while the opposite occurs in winter.

To quantify the impact of MLD variations on SST, the following quantities are computed from the composite net surface heat flux and MLD (Fig. 10b):

$(1 / \rho c)\left(Q_{w} / H_{m}-Q_{c} / H_{m}\right)$

$(1 / \rho c)\left(Q_{w} / H_{a n}-Q_{c} / H_{a n}\right)$

$(1 / \rho c)\left(Q_{w} / H_{w}-Q_{c} / H_{c}\right)$

where $Q_{w}$ and $Q_{c}$ are the average net surface heat flux during warm events and cold events, respectively, $H_{w}$ and $H_{c}$ are MLD during warm events and cold events respectively, $H_{a n}$ is the annually varying MLD, $H_{m}$ is the annual mean MLD, and 
$\rho$ and $\mathrm{c}$ are the density and specific heat of sea water respectively. The influence of the annual cycle in MLD on the anomalous SST can be quantified by comparing $\left(Q_{w} / H_{m}-Q_{c} / H_{m}\right)$ with $\left(Q_{w} / H_{a n}-Q_{c} / H_{a n}\right)$. The maximum value of $\left(Q_{w} / H_{m}-\right.$ $\left.Q_{c} / H_{m}\right)$ during boreal winter is about a half of $\left(Q_{w} / H_{a n}-Q_{c} / H_{a n}\right)$, indicating that the ENSO-induced warming is increased by about a factor of two due to the annual shoaling of the mixed layer in winter.

The impact of interannual variations in MLD on SST anomalies can be quantified by comparing $\left(Q_{w} / H_{a n}-Q_{c} / H_{a n}\right)$ with $\left(Q_{w} / H_{w}-Q_{c} / H_{c}\right)$. The interannual variation of MLD during boreal fall significantly affects the SST (Fig. 10b). Since the mixed layer during warm events is deeper in fall, $\left(Q_{w} / H_{w}-Q_{c} / H_{c}\right)$ tends to be more negative, which enhances anomalous cooling during this season. During boreal winter, $\left(Q_{w} / H_{a n}-Q_{c} / H_{a n}\right)$ is about $10 \%$ smaller than $\left(Q_{w} / H_{w}-Q_{c} / H_{c}\right)$ since the mixed layer is shallower during warm events.

The shallow mixed layer in winter $(\sim 20 \mathrm{~m})$ also implies that penetration of solar radiation through the base of the mixed layer may be significant. The effect of increased solar radiation passing through the base of the mixed layer, when the mixed layer is warming rapidly in winter during El Nino, would be to reduce the sensitivity of the mixed layer temperature to the anomalous surface heat flux forcing. This effect is quantified by computing $-\left(Q_{s w h w} / H_{w}-Q_{s w h c} / H_{c}\right)$, where $Q_{s w h w}$ and $Q_{s w h c}$ are the penetrative component of solar radiation at the depth of the mixed layer during warm and cold events respectively. During boreal winter, the magnitude of $-\left(Q_{s w h w} / H_{w}-Q_{s w h c} / H_{c}\right)$ is about $1 / 3$ of $\left(Q_{w} / H_{w}-Q_{c} / H_{c}\right)$ (Fig. 10b), indicating that ENSO-induced warming is significantly reduced due to the penetration of solar radiation. Note that $\left(Q_{w} / H_{w}-Q_{c} / H_{c}\right)-\left(Q_{s w h w} / H_{w}-Q_{s w h c} / H_{c}\right)$ is close to the actual SST tendency (not shown, but can be inferred from Fig. 7)

The anomalous entrainment heat flux at the base of the mixed layer (not shown) 
acts together with the surface heat flux to cool the mixed layer in boreal summer (when the mixed layer deepens) and to warm the mixed layer in winter (when the mixed layer shoals). The amplitude never exceeds $3 \mathrm{~W} / \mathrm{m}^{2}$, which is much smaller than the surface heat flux in winter but is comparable to the surface cooling in summer.

The composite SST anomalies from the MLM experiment averaged over $10^{\circ} \mathrm{N}$ $10^{\circ} \mathrm{S}$ across the Indian Ocean are shown in Fig. 11a. The model reproduces the observed seasonally phased-locked behavior in the eastern Indian Ocean (see Fig 2) and the development of the basin-wide warm anomaly by mid-winter. In the west, the anomalous surface flux forcing creates positive SST anomalies in winter that contributes to the basin-wide warming. However, the simulated warming of the western Pacific Ocean is weaker than observed and occurs two seasons too late. As a result, the cold SST anomaly extends too far to the west along the equator during autumn (Fig. 11b).

The observed anomalous zonal SST gradient along the equator in the Indian Ocean, i.e. the "Indian Ocean dipole", is at its maximum in boreal autumn. A measure of the dipole is obtained here from the difference between SSTs in the western and eastern boxes, shown in Figs. $2 \mathrm{~b}$ and $11 \mathrm{~b}$. The time series of the dipole index from the observed SST and the MLM experiments are shown in Fig. 12. The observed index is positive in all El Nino years and negative in all La Nina years, confirming that the anomalous zonal gradient is highly influenced by ENSO. The correlation (r) with Nino3.4 SST is 0.77, which is also consistent with the EOF analysis described in Sec. 3 (Fig. 3). The index from the MLM experiments is also highly correlated with the Nino3.4 SST index $(r=0.75)$ and with the observed dipole index $(r=0.62)$. The correlation of observed SSTs in the eastern box with those from MLM experiments is 0.38 (after removing linear trends). The correlation is much higher $(\mathrm{r}=0.78)$ for 
El Nino and La Nina years, confirming that ENSO-induced anomalous surface fluxes are responsible for explaining much of observed SST anomalies in the eastern Indian Ocean associated with ENSO.

The standard deviation (SD) of the index from the MLM experiment $(\mathrm{SD}=0.21)$ is more than $50 \%$ smaller than observed $(\mathrm{SD}=0.50)$. This difference stems mainly from lack of amplitude in the western box in the model, where the warming is not generated in early autumn during El Nino. In the following section we hypothesize that the exclusion of a dynamical response to the remotely forced surface wind variations is the source of this discrepancy in the western Indian Ocean. 


\section{Discussion and Conclusions}

In this study, we examined the SST anomalies in the tropical Indian Ocean during ENSO, including the processes that create the anomalies and their evolution over the seasonal cycle. We explored the extent to which SST anomalies are generated by the atmospheric bridge, i.e. atmospheric changes associated with El Nino conditions in the Pacific drive Indian Ocean SST anomalies via surface heat fluxes and other vertical processes. The atmospheric bridge hypothesis was tested using NCEP reanalysis and three sets of AGCM experiments: i) GOGA - observed SSTs specified globally; ii) EPOGA - Observed SSTs specified in the eastern tropical Pacific and climatological SSTs elsewhere and iii) MLM - observed SSTs specified in the eastern tropical Pacific and the AGCM coupled to a mixed layer model elsewhere over the global oceans.

During the developing stages of El Nino in boreal summer and autumn, SSTs warm in the central Pacific and convection shifts eastward towards the date line. The Walker circulation weakens, resulting in anomalous easterlies and reduced rainfall over the eastern Indian Ocean (e.g., Rassumusson and Carpenter 1982). Reduced rainfall is associated with increased surface short wave radiation, while the anoma-

lous surface easterlies act to enhance the climatological easterly winds. Evaporative cooling increases and the mixed layer deepens. The enhanced evaporative cooling dominates over increased short wave radiation, hence the remotely forced surface flux acts to cool the eastern Indian Ocean.

During boreal winter, the climatological winds across the south eastern Indian Ocean become westerly, associated with the onset of the Australian summer monsoon. The persistent anomalous easterlies then act to reduce the wind speed and thus the evaporative cooling. Hence the reduced evaporative cooling and increased short wave radiation warm the underlying ocean. One-dimensional oceanic processes, especially 
shoaling of the mixed layer due to the weak winds significantly enhances the warming.

The evolution of the anomalous surface flux forcing is well simulated in all three experiments and the SST anomalies in the MLM experiment resemble observations in the eastern Indian Ocean. The remotely forced SST anomaly during boreal fall in the eastern part of the basin significantly contribute to "the Indian Ocean dipole". In addition, the basin-scale warm anomaly that peaks in late boreal winter, a few months after Nino3.4 peaks (e.g., Klein et al. 1999), also appears to be governed by remotely forced surface heat fluxes.

While capturing some of the important features of the evolution of SST in the Indian Ocean during the ENSO cycle, some features are not well simulated by the one-dimensional mixed layer model employed here. For instance, the net surface heat flux in both reanalysis and the AGCM experiments act to cool the western Indian Ocean from August to October when the observed SSTs in the western Indian Ocean warm rapidly. The absence of surface warming in the western Indian Ocean in the MLM results in a weak anomalous zonal SST gradient across the basin in boreal autumn. Venzke et al. (2000), based on analysis of a coupled GCM, suggested that SST changes in the western Indian Ocean associated with ENSO are primarily caused by latent heat flux anomalies. However, Klein et al. (1999), using long term ship and satellite data, indicated that the net surface heat flux associated with ENSO appears to be negative (cooling) in the southwestern Indian Ocean. Ocean dynamics, which are not included in the MLM experiment, likely play an important role in the SST changes in the western Indian Ocean (e.g., Murtugudde and Busalacchi 1999). During boreal summer and early autumn, the remotely driven surface easterlies should drive a dynamical response in the equatorial Indian Ocean. The adjustment to these easterlies takes the form of a downwelling Rossby wave to the west and upwelling Kelvin wave to the east. The downwelling Rossby wave would be expected to cause anomalous 
warming once it reaches the central Indian Ocean, where the mean thermocline is shallow (e.g., Xie et al. 2002). This downwelling Rossby wave, would also be expected to arrest the tropical cooling driven by the surface heat flux, which leads to simulation of an overly-extensive cold tongue extending into the western Indian Ocean (Fig. 11).

The upwelling Kelvin wave would likely contribute to the cooling in the east during boreal summer and autumn. In addition, the easterlies would promote coastal upwelling along the north-west to south-east tilted coasts of Sumatra and Java (e.g., Murtugudde and Busalacchi 1999). However, the change in sign of the evaporative cooling, and the rapid shoaling of the mixed layer once the Australian summer monsoon commences seems to be critical for the rapid demise of the anomalous zonal gradient in early winter, since the eastern Indian Ocean warms rapidly while the anomalous winds are still easterly (Fig. 9).

While we have demonstrated the importance of seasonal evolution of surface heat fluxes using the ensemble mean, there is the spread among the ensemble members. Alexander et al. (2002) discussed the spread among 16 ensemble members in the MLM experiments. They demonstrated that the size of the ensemble is adequate to obtain significant results in the central north Pacific Ocean. We have also calculated the composite surface fluxes in the tropical Indian Ocean for the 16 individual MLM simulations (not shown). The spread of the latent heat flux $\left(5-10 \mathrm{~W} / \mathrm{m}^{2}\right)$ is similar to that in the central North Pacific. In addition, all 16 ensemble members indicate cooling during boreal fall and warming during the winter in the eastern Indian Ocean.

An issue that we have not addressed is the possible feedback of the induced SST anomalies onto the local circulation and rainfall. Evidence for a feedback is seen in Fig. 8, where the latent heat flux in the eastern Indian Ocean from the EPOGA experiment is stronger than the MLM experiments during boreal autumn and weaker during winter. This difference results from using climatological SST 
boundary conditions in the Indian Ocean in the EPOGA experiment, which are too warm in the eastern Indian Ocean in autumn and too cold in winter. The feedback on the latent heat flux and local rainfall anomalies are modest, as will be discussed in a forthcoming study.

In summary, much of the observed SST variation in the tropical Indian Ocean during ENSO can be accounted for by one-dimensional ocean process forced by surface flux variations remotely driven from the tropical Pacific. In particular, the behavior in the eastern Indian Ocean, where during El Nino SSTs initially cool in boreal summer and early autumn and then abruptly warm in early winter, is well explained. So too is the development of a basin wide warm anomaly that lags the peak warming in the eastern Pacific by a few months. The development of a strong anomalous zonal SST gradient in boreal autumn is not well simulated, mainly due to the lack of development of an opposite-signed anomaly in the western Indian Ocean. Allowing the dynamical response in the ocean to affect the SST would seem to alleviate much of this deficiency and should be a future area of study. 


\section{Acknowledgment}

Constructive comments by two reviewers are gratefully acknowledged. Support for this work was provided by CLIVAR-Pacific Grants from NOAA's office of Global Programs. 


\section{References}

Alexander, M. A., and J. D. Scott, 1997: Surface flux variability over the North Pacific and North Atlantic Oceans. J. Climate, 10, 2963-2978.

Alexander, M. A., J. D. Scott, and C. Deser, 2000: Processes that influence sea surface temperature an ocean mixed layer depth variability in a coupled model. J. Geophys. Res. - Oceans, 105, 16,823-16,842.

Alexander, M. A., I. Blade, M. Newman, J. R. Lanzante and N.-C. Lau, 2002: The atmospheric bridge: The influence of ENSO teleconnections on air-sea interaction over the Global Oceans. J. Climate, 15, 2205-2231.

Baquero-Bernal, A., M. Latif, and S. Legutke, 2002: On dipolelike variability of sea surface temperature in the tropical Indian Ocean. J. Clim., 15, 1358-1368.

Chambers, D. P., B. D. Tapley, and R. H. Stewart, 1999: Anomalous warming in the Indian Ocean coincident with El Nino. J. Geophys. Res., 104, 3035-3047.

Flohn, H., 1986: Indonesian droughts and their teleconnections. Berliner Geographishe Studien, 20, 251-265.

Gaspar, P., 1988: Modeling the seasonal cycle of the upper ocean. J. Phys. Oceanogr. $18,161-180$.

Goddard, L and N. E. Graham 1999: Importance of the Indian Ocean for simulating rainfall anomalies over eastern and southern Africa. J. Geophys. Res., 104, 19099-19116.

Gordon, H. B., and W. Stern, 1982: A description of the GFDL global spectral model. Mon. Wea. Rev., 110, 625-644. 
Hackert, E. C., and S. Hastenrath, 1986: Mechanisms of Java rainfall anomalies. Mon. Wea. Rev., 114, 745-757.

Hastenrath, S., A. Nicklis and L. Greischar, 1993: Atmospheric-hydrospheric mechanisms of climate anomalies in the western equatorial Indian Ocean. J. Geophys. Res., 98, 20219-20235.

Hendon H. H., 2002: Indonesian rainfall variability: Impact of ENSO and local air-sea interaction. J. Climate (submitted).

Kalnay, E., and Co-authors, 1996: The NCEP/NCAR 40-Year Reanalysis Project. Bull. Amer. Meteor. Soc., 77, 437-471.

Klein, S. A., B. J. Soden and N. C. Lau 1999: Remote sea surface temperature variations during ENSO: Evidence for a tropical atmospheric bridge. J. Climate., $12,917-932$.

Kiladis, G. N., and H. F. Diaz, 1989: Global climatic anomalies associated with extremes in the Southern Oscillation. J. Climate, 2, 1069-1090.

Lau, N. C., 1981: A diagnostic study of recurrent meteorological anomalies appearing in a 15-year simulation with a GFDL general circulation model. Mon. Wea. Rev., 109, 2287-2311.

Lau, N. C. and M. J. Nath, 2000: Impact of ENSO on the variability of the AsianAustralian monsoons as simulated in GCM experiments. J. Climate, 13, 42874309.

Lau, N. C. and M. J. Nath, 2003: Atmosphere-ocean variations in the Indo-Pacific sector during ENSO episode. J. Climate, 16, 3-20. 
Manabe, S., and D. G. Hahn 1981: Simulation of atmospheric variability. Mon. Wea. Rev., 109, 2260-2286.

Monterey, G. I., and S. Levitus, 1997: Climatological cycle of mixed layer depth in the world ocean. U.S. Gov. Printing Office, NOAA Nesdis, 5pp.

Murtugudde, R., and A. J. Bussalacchi, 1999: Interannual variability of the dynamics and thermodynamics of the tropical Indian Ocean. J. Climate, 12, 2300-2326.

Murtugudde, R., J. P. McCreary Jr. and A. J. Bussalacchi, 2000: Oceanic processes associated with anomalous events in the Indian Ocean with relevance to 19971998. J. Geophys. Res., 105, 3295-3306.

Nicholls, N., 1981: Air-sea interaction and the possibility of long-range weather prediction in the Indonesian Archipelago. Mon. Wea. Rev., 109, 2435-2443.

Nicholls, N., 1984: The Southern Oscillation and Indonesian seas surface temperature. Mon. Wea. Rev., 112, 424-432.

Nicholls, N. 1989: Sea surface temperature and Australian winter rainfall. J. Climate, 2, 965-973.

Palmer, T. N. and D. A. Mansfield 1984: Response of two atmospheric general circulation models to sea-surface temperature anomalies in the tropical east and west Pacific. Nature, 310, 483-485.

Rasmusson, E. M., and T. H. Carpenter, 1982: Variations in tropical sea surface temperature and surface wind fields associated with the Southern Oscillation/El Nino. Mon. Wea. Rev., 110, 354-384. 
Reverdin, G., D. Cadet and D. Gutzler, 1986: Interannual displacements of convection and surface circulation over the equatorial Indian Ocean. Q. J. R. Met. Soc., 112, 43-67.

Ropelewski, C. F., and M. S. Halpert, 1987: Global and regional scale precipitation patterns asociated with the El Nino/Southern Oscillation. Mon. Wea. Rev., $115,1606-1626$.

Rowell, D. P., 2001: Teleconnections between the tropical Pacific and the Sahel. Quart. J. Roy. Meteor. Soc., 127, 1683-1706.

Saji, N. H., B. N. Goswami, P. N. Vinayachandran and T. Yamagata 1999: A dipole mode in the tropical Indian Ocean. Nature, 401, 360-363.

Smith, T. M., R. W. Reynolds, R. E. Livezey, and D. C. Strokes, 1996: Reconstruction of historical sea surface temperatures using empirical orthogonal functions. J. Clim., 9, 1403-1420.

Trenberth, K. E., 1997: The definition of El Nino. Bull. Amer. Met. Soc., 78, 2771-2778.

Venzke, S., M. Latif and A. Villwock 2000: The coupled ECHO-2. Part II: Indian ocean response to ENSO. J. Clim., 13, 1371-1383.

Webster, P. J., A. M. Moore J. P. Loschnig and R. R. Leben 1999: Coupled oceanatmosphere dynamics in the Indian Ocean during 1997-98. Nature, 401, 356360.

Xie, S. P., H. Annamalai, F. A. Schott and J. P. McCreary 2001: Structure and mechanism of south Indian Ocean climate variability. J. Clim., 15, 864-878. 
Yu, L. and M. M. Rienecker 1999: Mechanisms for the Indian Ocean warming during the 1997-1998 El Nino. Geophys. Res. Lett., 26, 735-738. 


\section{Figure captions}

Figure 1: Composite SST anomalies (Warm-Cold) averaged for the Nino3.4 $\left(5^{\circ} \mathrm{N}\right.$ $\left.5^{\circ} \mathrm{S}, 120^{\circ} \mathrm{E}-170^{\circ} \mathrm{W}\right)$ (solid line, square), eastern Indian Ocean $\left(100^{\circ} \mathrm{E}-120^{\circ} \mathrm{E}, 1^{\circ} \mathrm{S}-5^{\circ} \mathrm{S}\right)$ (dashed line, open circle) and western Indian Ocean $\left(50^{\circ} \mathrm{E}-60^{\circ} \mathrm{E}, 10^{\circ} \mathrm{S}-10^{\circ} \mathrm{N}\right)($ dotted line, closed circle)

Figure 2: (a) The composite SST averaged over $10^{\circ} \mathrm{S}-10^{\circ} \mathrm{N}$ from observations. (b) A map of the composite SST during September-November.

Figure 3: (a) First eigenvector of the observed SST during September-November. The eigenvector has been scaled for a one standard deviation anomaly of the principal component. (b) Time series of the PC-1 (solid line) and the Nino3.4 SST anomaly (dashed line) during September-November. The sign of the Nino3.4 SST is changed for the comparison. Both time series are normalized by the standard deviation.

Figure 4: (a) Composite net surface heat flux (solid lines) and observed SST (dashed

lines) averaged for the area $\left(100^{\circ} \mathrm{E}-120^{\circ} \mathrm{E}, 15^{\circ} \mathrm{S}-5^{\circ} \mathrm{S}\right)$. Closed (open) circles indicate surface heat fluxes from the NCEP reanalysis (GOGA experiments). Positive values of the surface heat flux indicate warming. (b) Same as (a) except for the area $\left(50^{\circ} \mathrm{E}\right.$ $\left.60^{\circ} \mathrm{E}, 10^{\circ} \mathrm{S}-10^{\circ} \mathrm{N}\right)$

Figure 5: Composite surface latent heat flux (solid lines) and short wave radiation (dashed lines) averaged for the area $\left(100^{\circ} \mathrm{E}-120^{\circ} \mathrm{E}, 15^{\circ} \mathrm{S}-5^{\circ} \mathrm{S}\right)$ from the NCEP reanalysis (closed circle) and the GOGA experiments (open circle). Positive values indicate warming. 
Figure 6: (a) Composite zonal winds at the surface averaged for the area $\left(100^{\circ} \mathrm{E}\right.$ $120^{\circ} \mathrm{E}, 15^{\circ} \mathrm{S}-5^{\circ} \mathrm{S}$ ) from the GOGA experiments (open circle) and NCEP reanalysis (closed circle). (b) Composite precipitation averaged for the area $\left(100^{\circ} \mathrm{E}-120^{\circ} \mathrm{E}, 15^{\circ} \mathrm{S}-\right.$ $5^{\circ} \mathrm{S}$ ) from the GOGA experiments (open circle) and NCEP reanalysis (closed circle).

Figure 7: Composite net surface heat flux (solid lines) and SST from the MLM experiments (dashed lines) averaged for the area $\left(100^{\circ} \mathrm{E}-120^{\circ} \mathrm{E}, 15^{\circ} \mathrm{S}-5^{\circ} \mathrm{S}\right)$. Net surface heat flux values are plotted for the GOGA experiments (open circle), EPOGA experiments (closed circle) and the MLM experiments (square). Positive values indicate warming.

Figure 8: Composite wind speed (solid lines) and latent heat flux (dashed lines) averaged for the area $\left(100^{\circ} \mathrm{E}-120^{\circ} \mathrm{E}, 15^{\circ} \mathrm{S}-5^{\circ} \mathrm{S}\right)$ from the GOGA experiments (open circle), the EPOGA experiments (closed circle) and the MLM experiments (square).

Figure 9: (a) Composite zonal winds averaged for the area $\left(100^{\circ} \mathrm{E}-120^{\circ} \mathrm{E}, 15^{\circ} \mathrm{S}-5^{\circ} \mathrm{S}\right)$ from the GOGA (open circle), EPOGA (closed circle) the MLM (square) experiments. (b) Annual cycle of zonal winds. The area and marks are same as in (a).

Figure 10: (a) Composite mixed layer depth for El Nino years (open circle) and La Nina years (closed circle). (b) Composites of $(1 / \rho c)\left(Q_{w} / H_{m}-Q_{c} / H_{m}\right)$ (open circle), $(1 / \rho c)\left(Q_{w} / H_{a n}-Q_{c} / H_{a n}\right)\left(\right.$ closed circle), $(1 / \rho c)\left(Q_{w} / H_{w}-Q_{c} / H_{c}\right)$ (open square) and $-(1 / \rho c)\left(Q_{s w h w} / H_{w}-Q_{s w h c} / H_{c}\right)$ (closed square). See text for the detail.

Figure 11: (a) The composite SST averaged over $10^{\circ} \mathrm{S}-10^{\circ} \mathrm{N}$ from the MLM experi- 
ments. (b) A map of the composite SST during September-November.

Figure 12: Time series of the area average SST difference between the eastern box and the western box shown in Fig. 2b during September- November from observations (upper panel) and the MLM experiments (lower panel). * indicates El Nino years and + indicates La Nina years. Positive values indicate that the SST in the western box is warmer than in the eastern box. 

Fig. 1

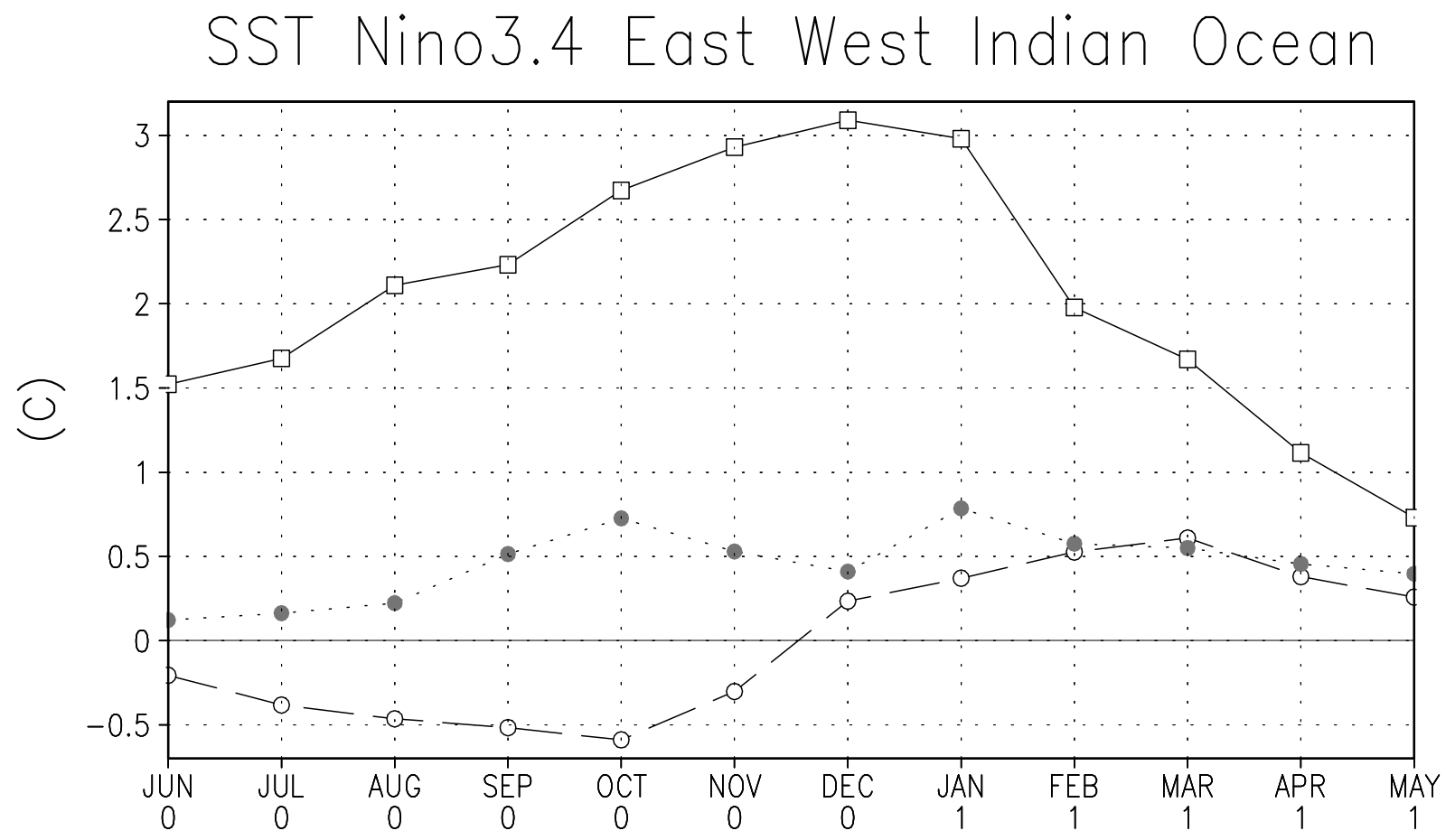


Fig. 2

SST Observation 10N-10S Wam-Cold

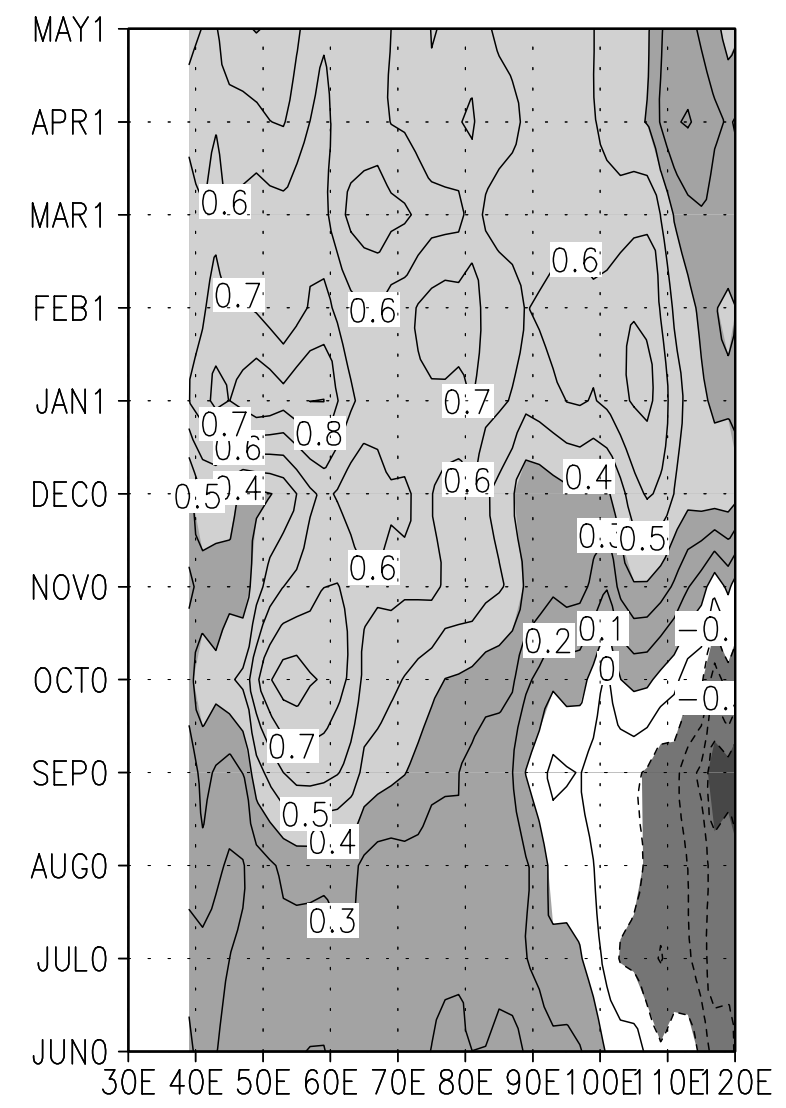

(a)

(b)

\section{SST Observation SON Warm-Cold}

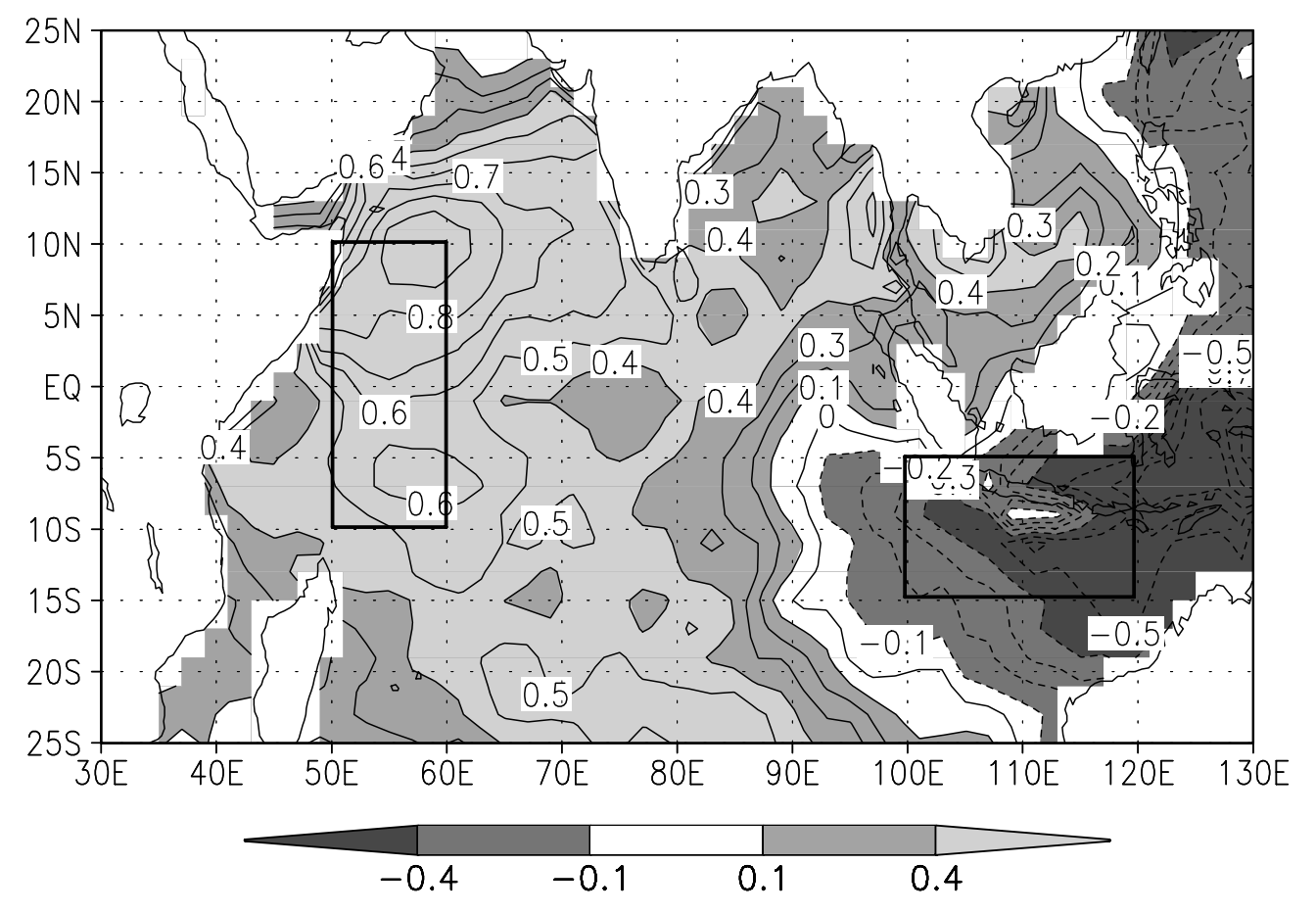


Fig. 3a

\section{EOF 1 SST SON 43.2\%}

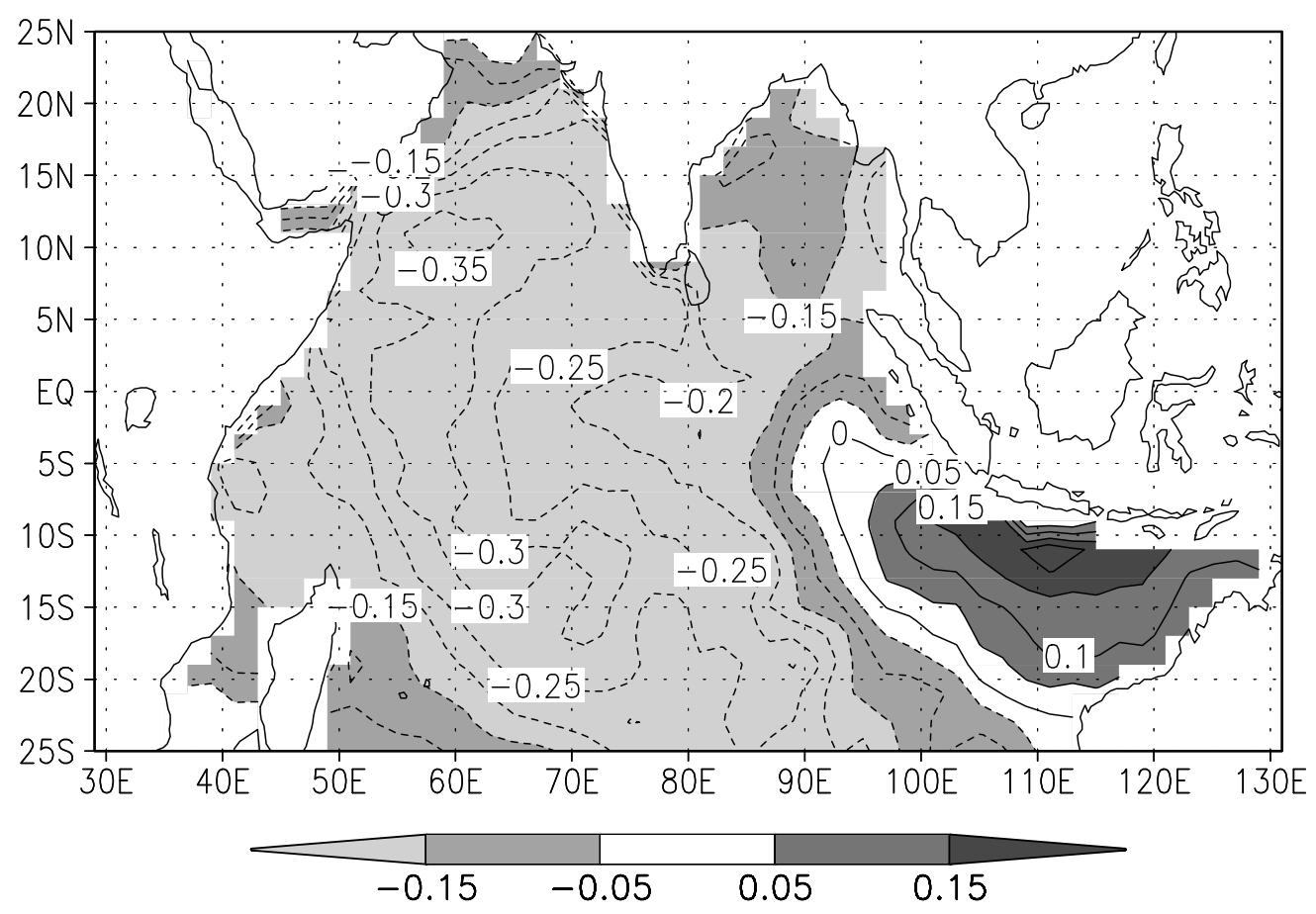


Fig. 3b

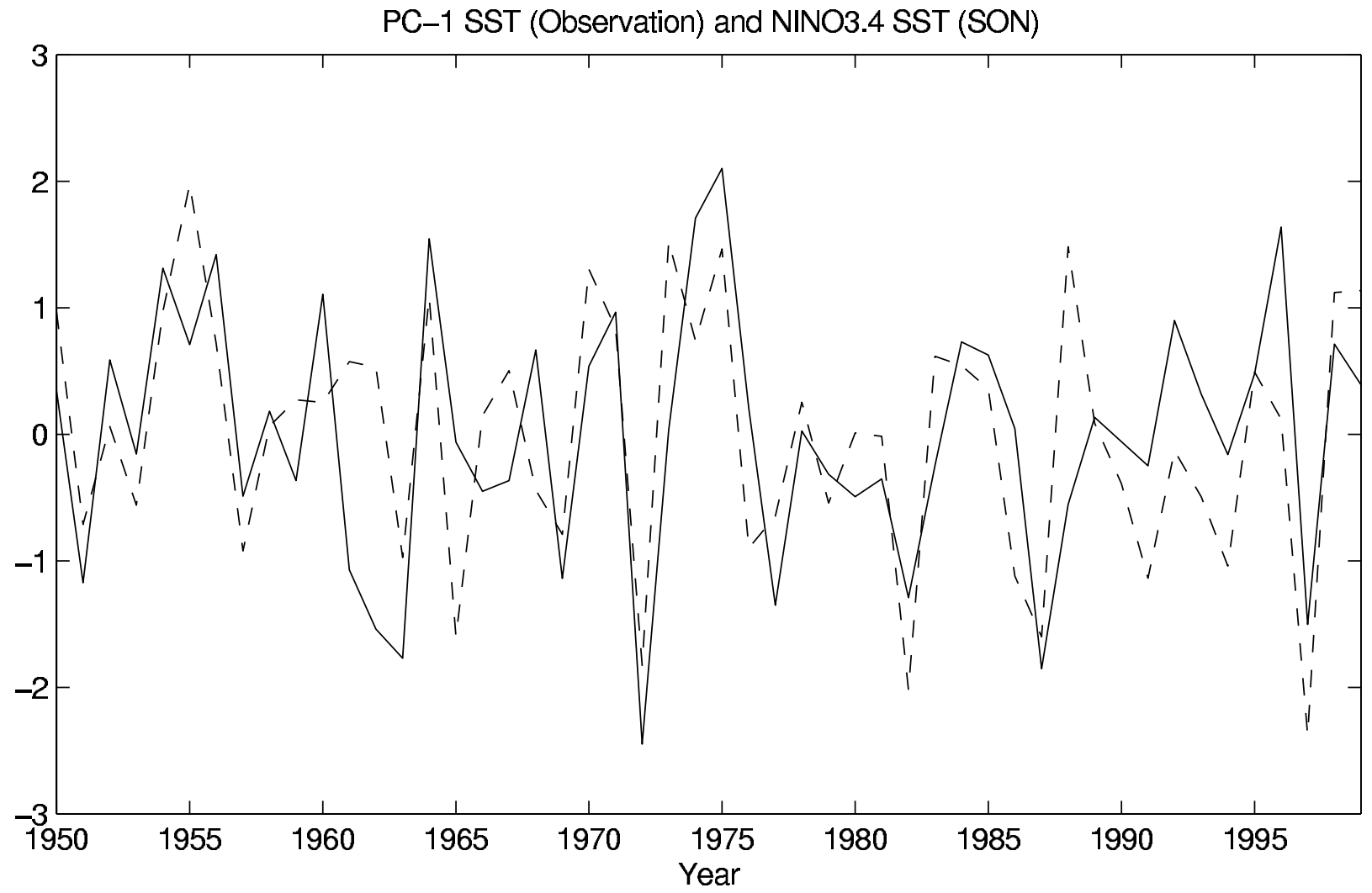


Fig. 4

(a)

Surface Heat Flux and SST 100E-120E 15S-5S

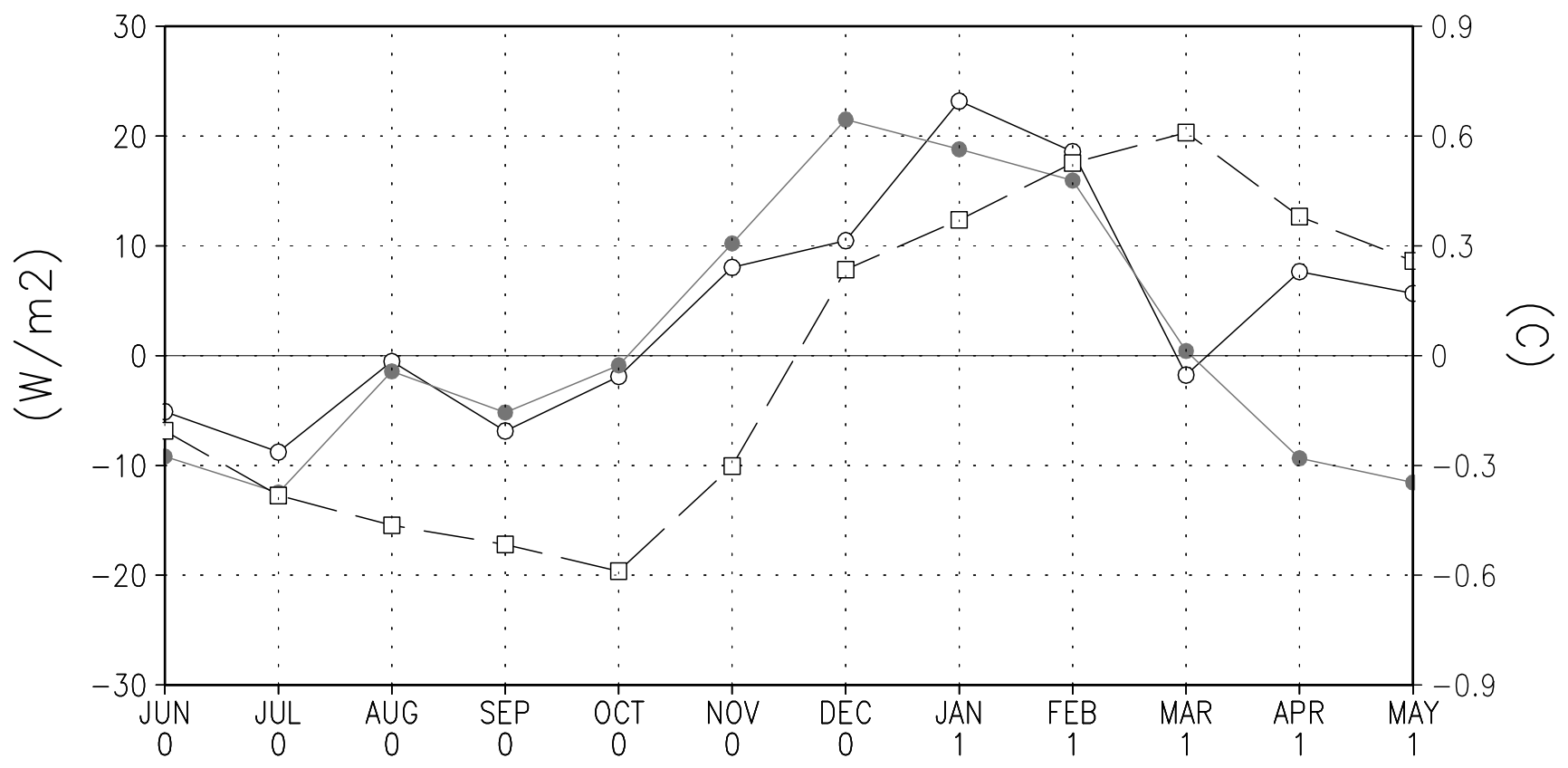

(b)

Surface Heat Flux and SST 50E-60E 10S-10N

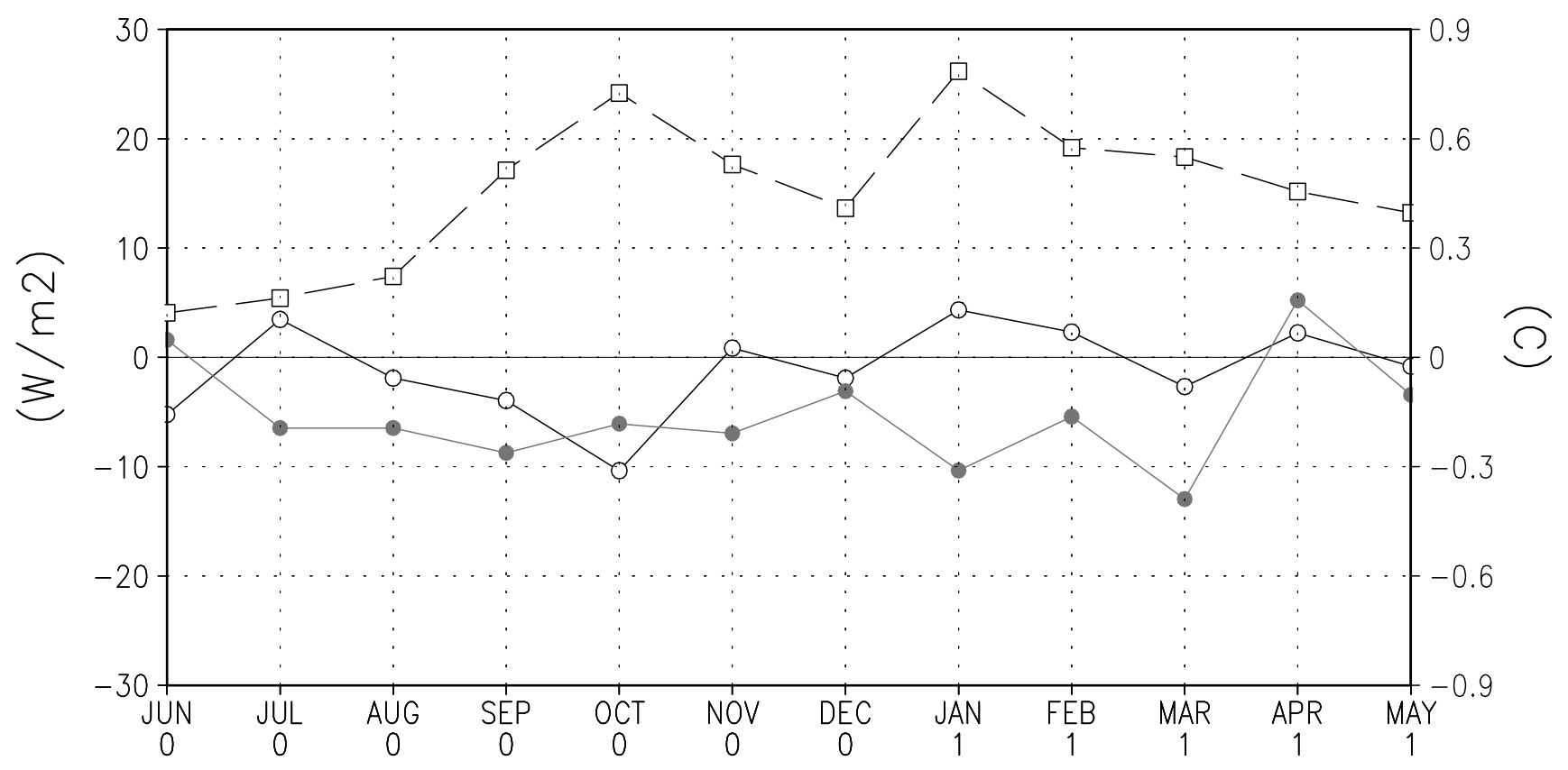


Fig. 5

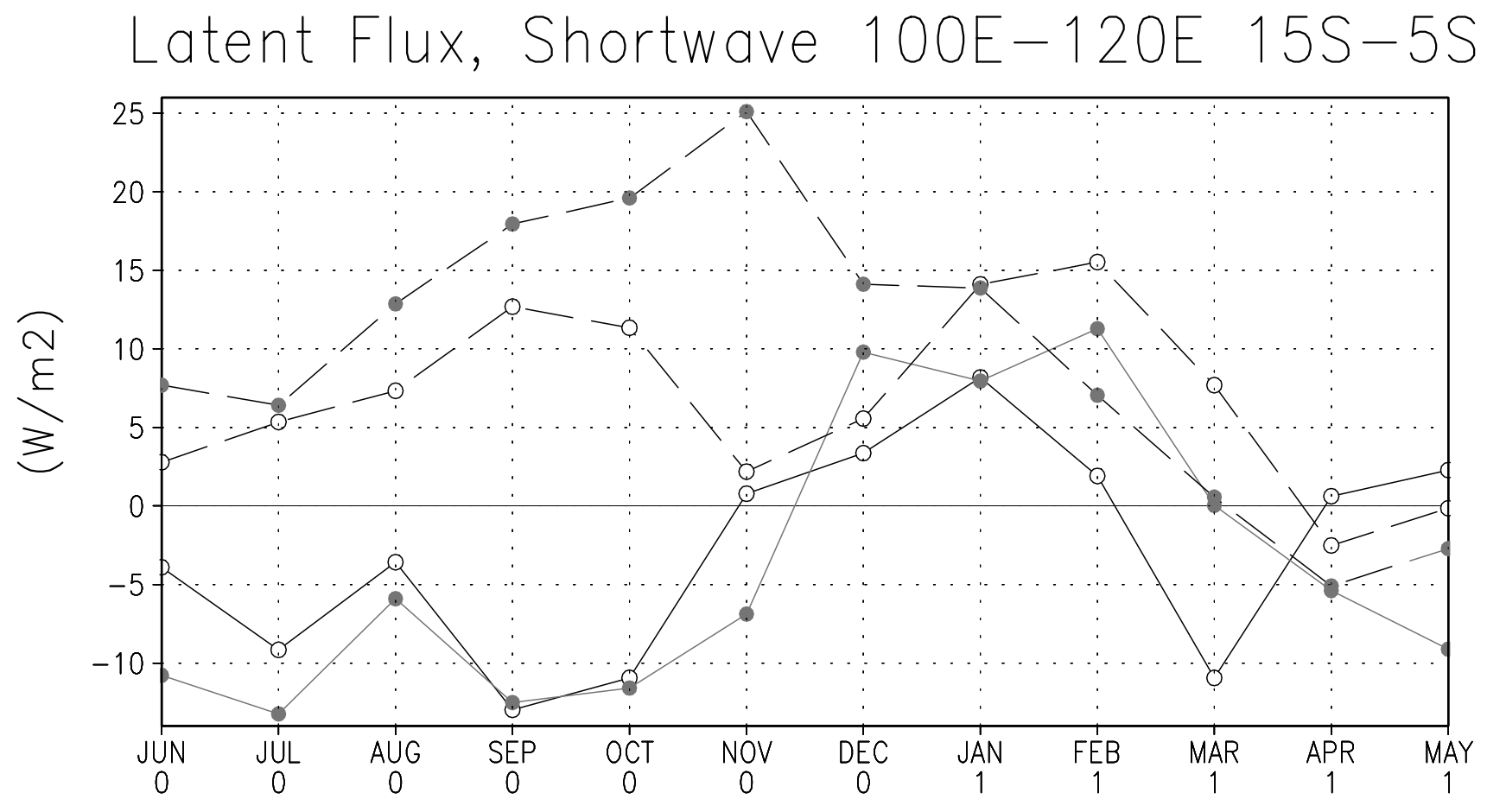


Fig. 6

(a)

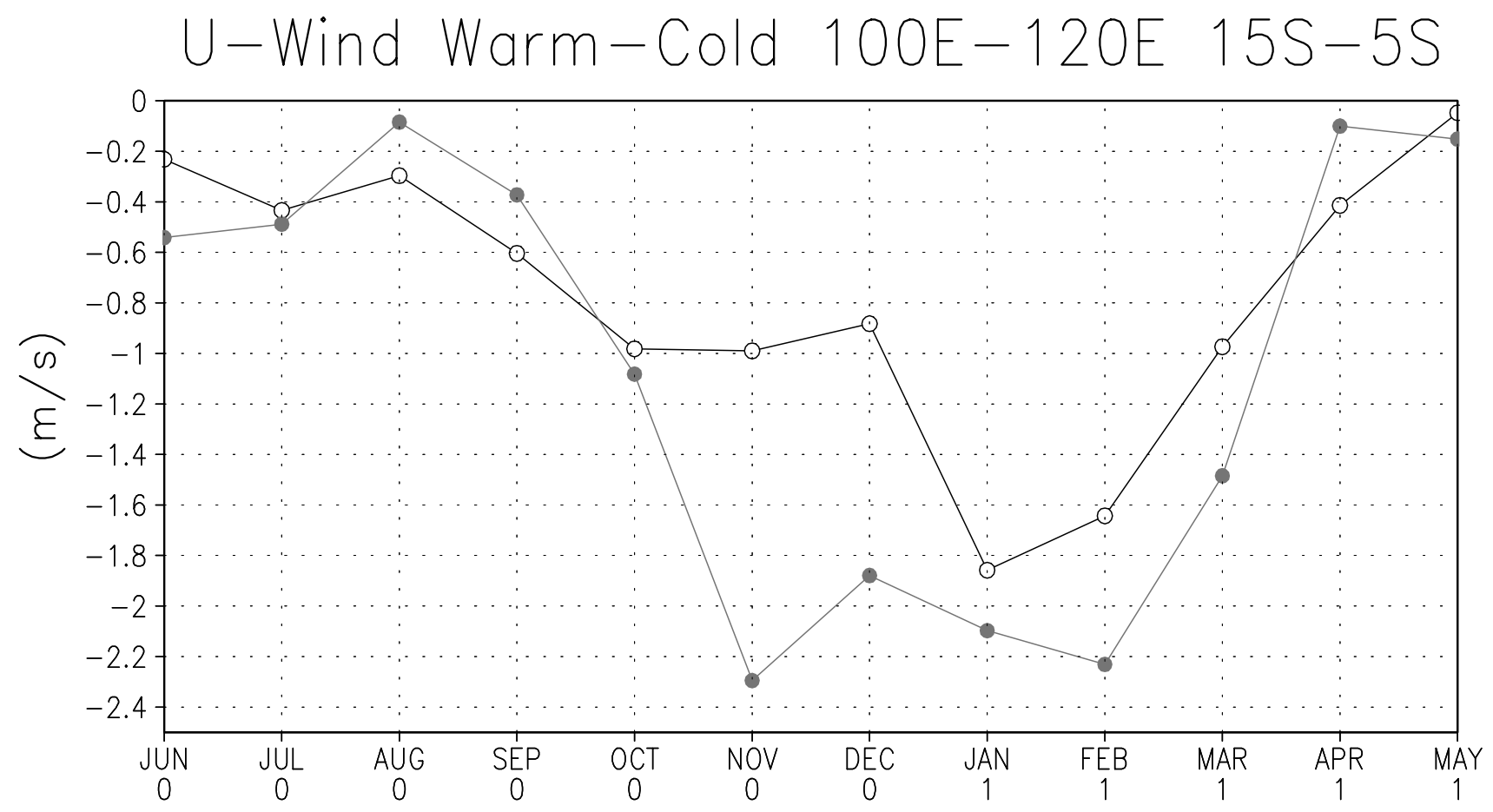

(b)

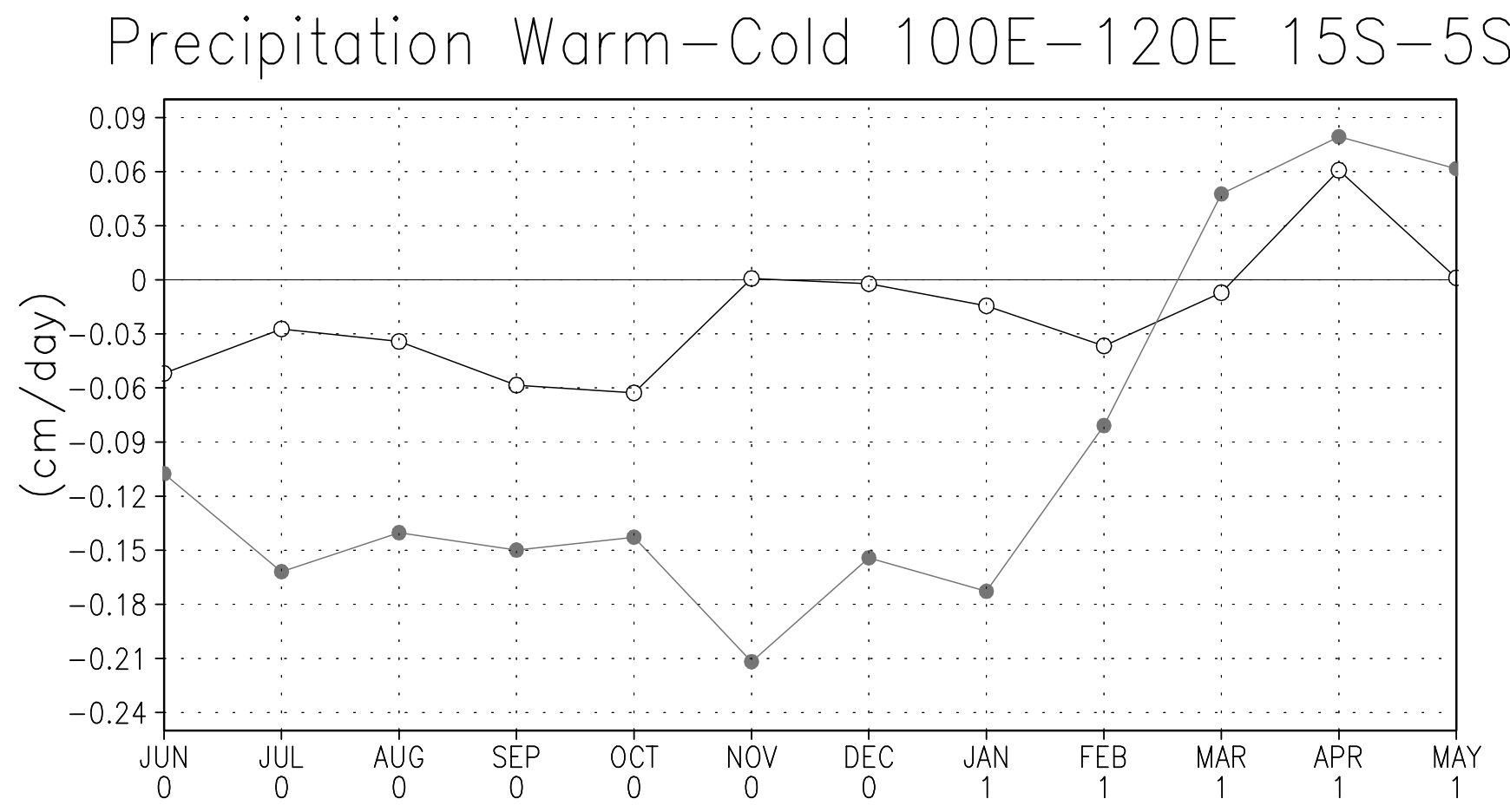


Fig. 7

Surface Heat Flux and SST 100E-120E 15S-5S

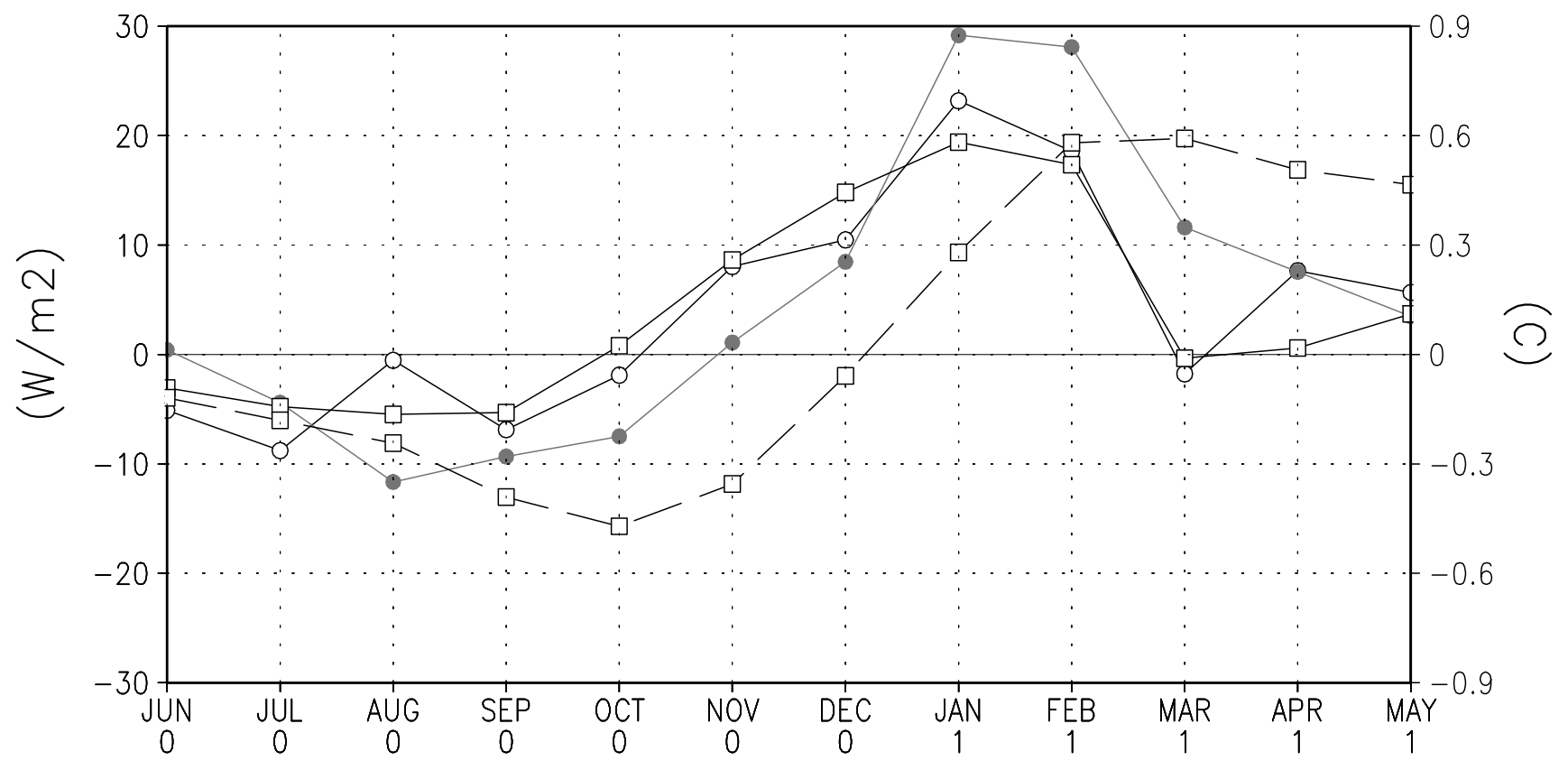


Fig. 8

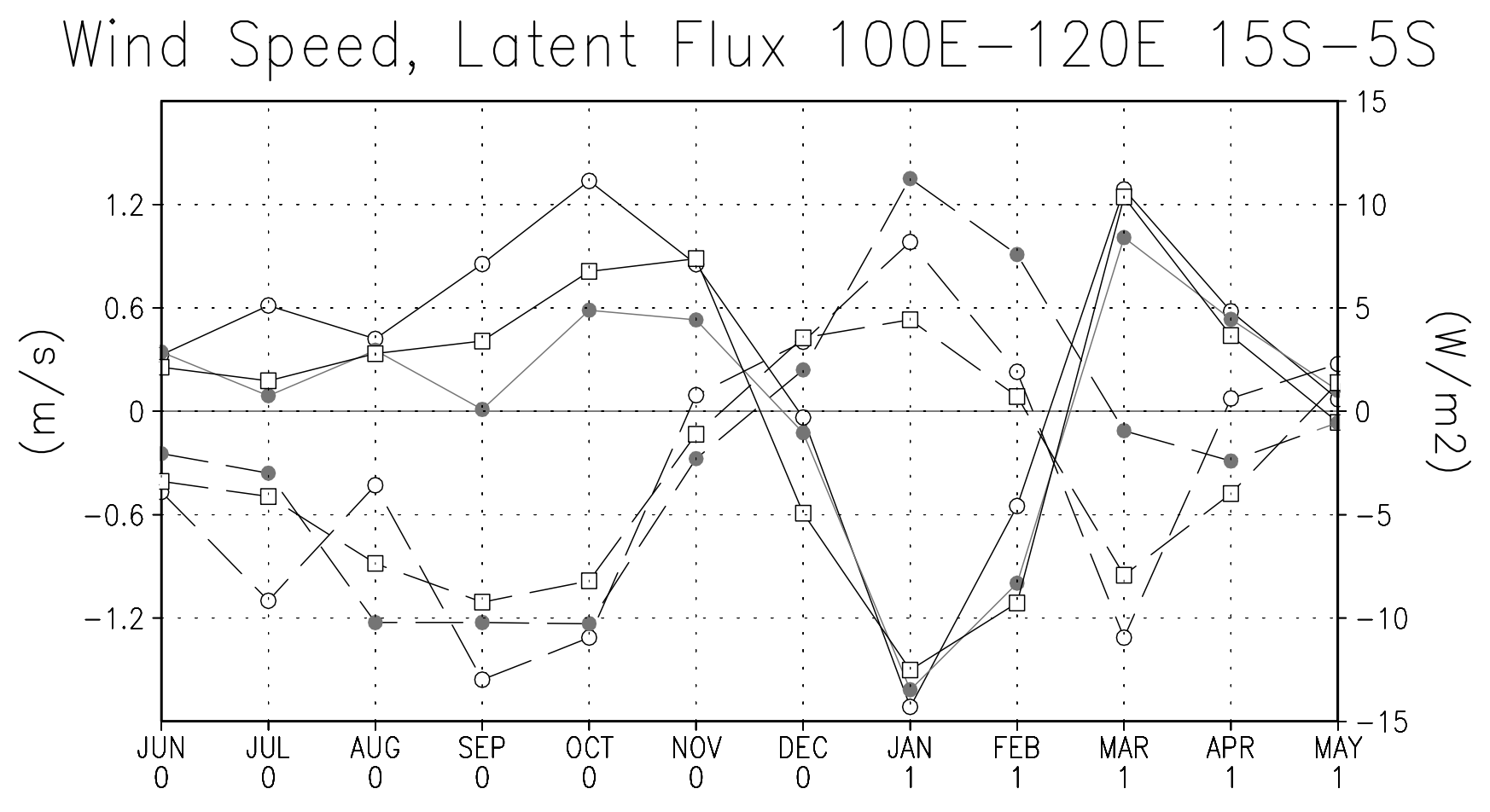


Fig. 9

(a)

Zonal Wind Warm-Cold 100E-120E 15S-5S

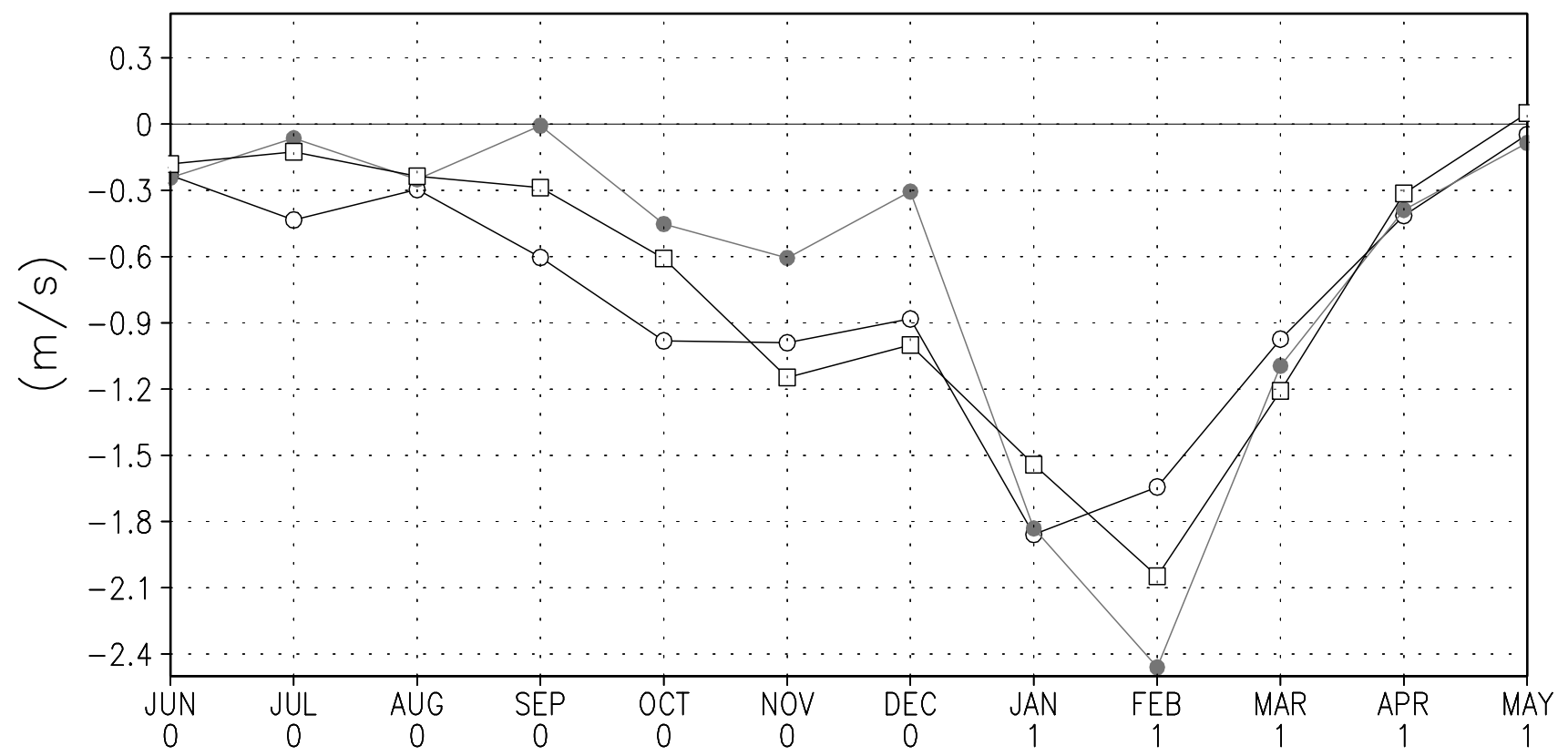

(b)

Zonal Wind Annual Cycle 100E-120E 15S-5S

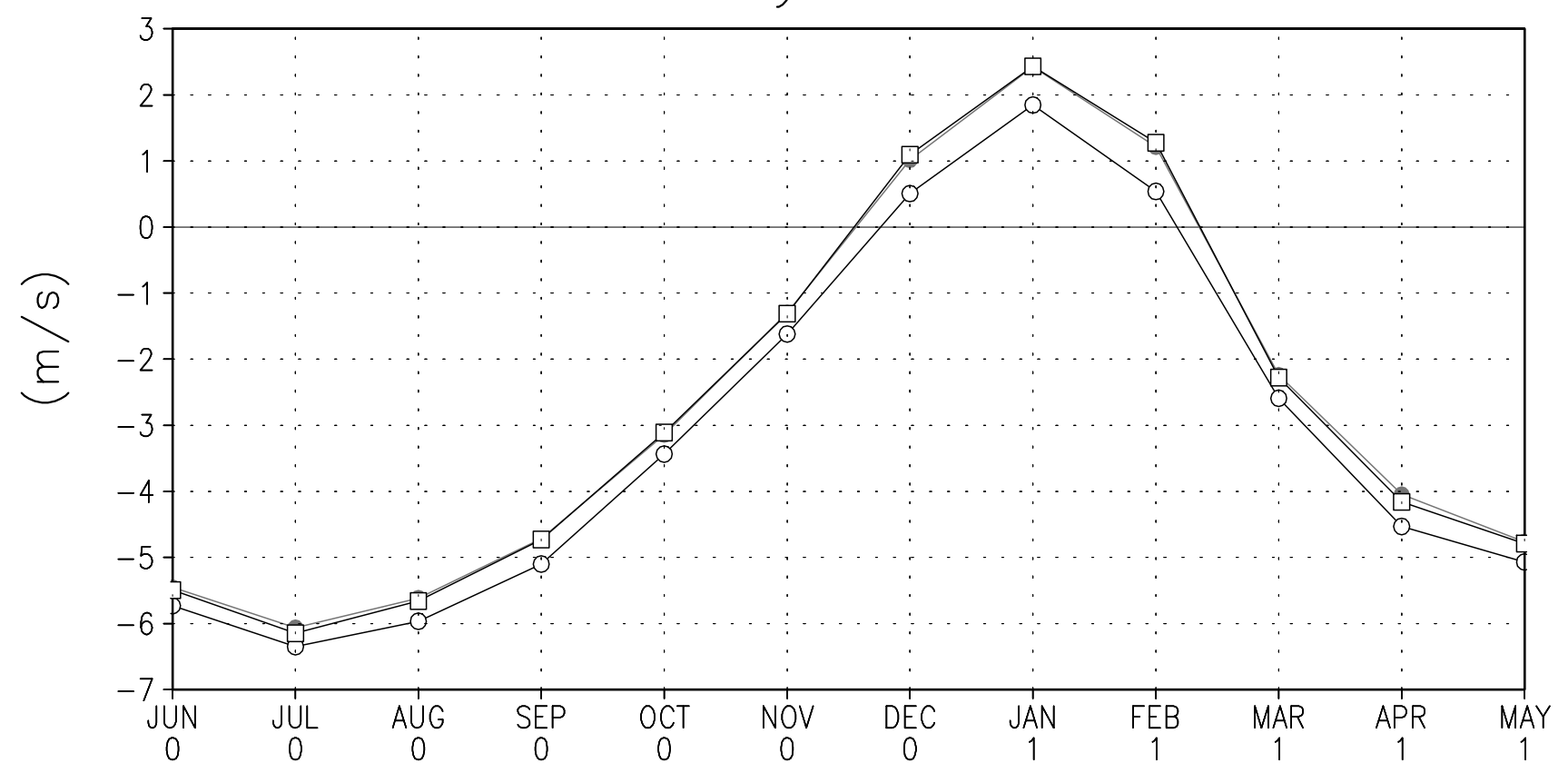


Fig. 10

(a)

Mixed Layer Depth 100E-120E 15S-5S

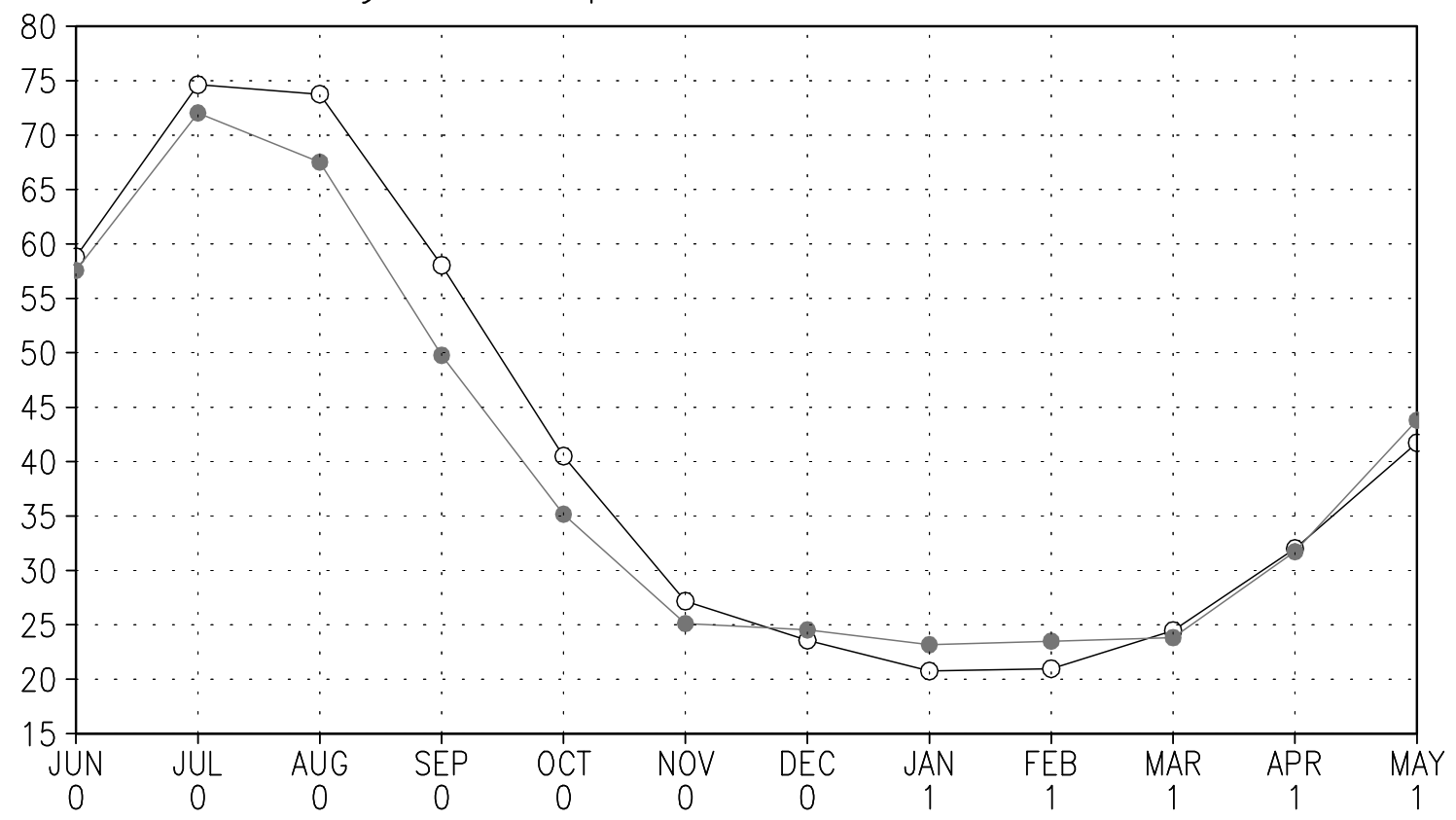

(b)

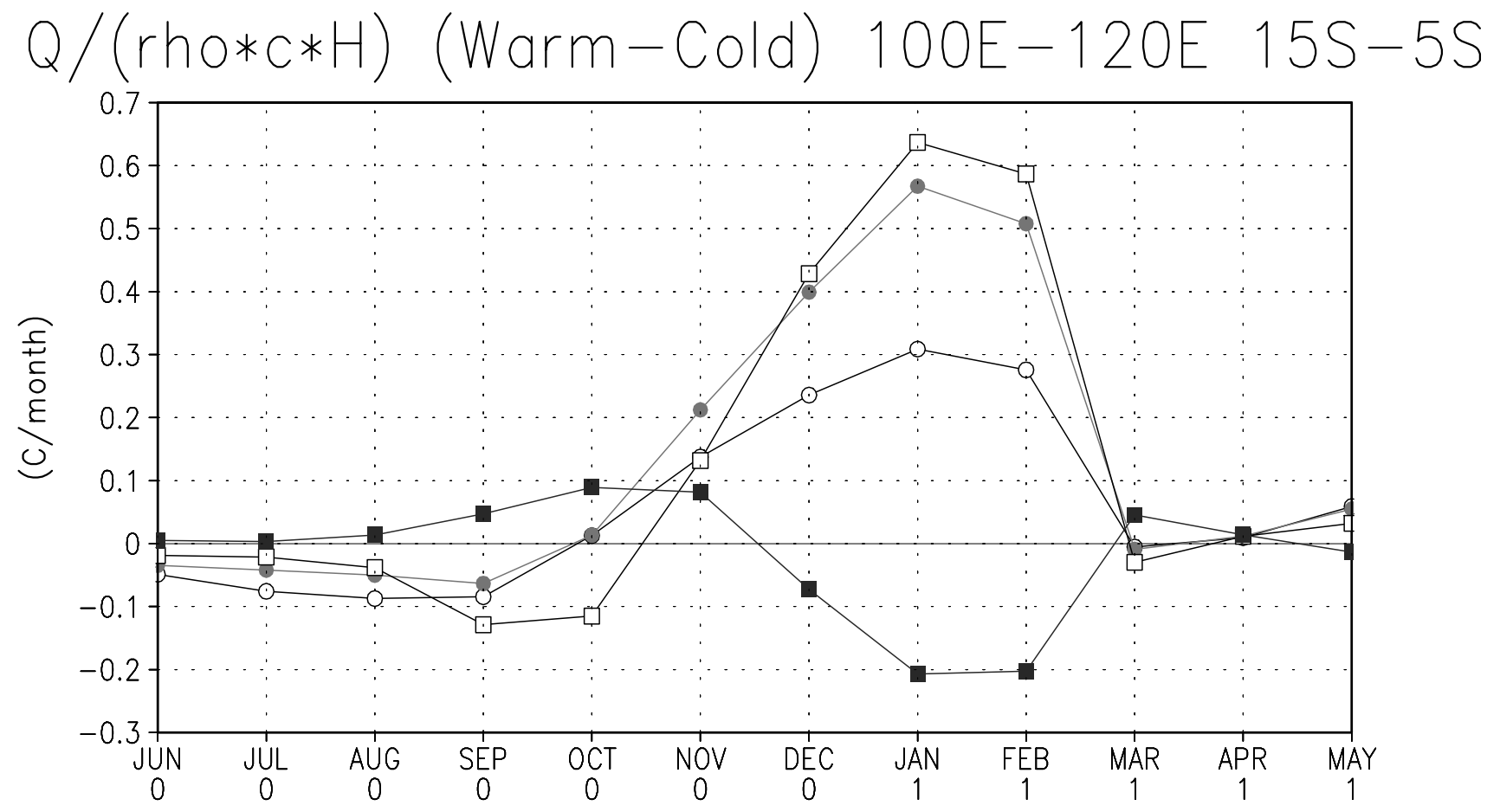


Fig. 11

(a)
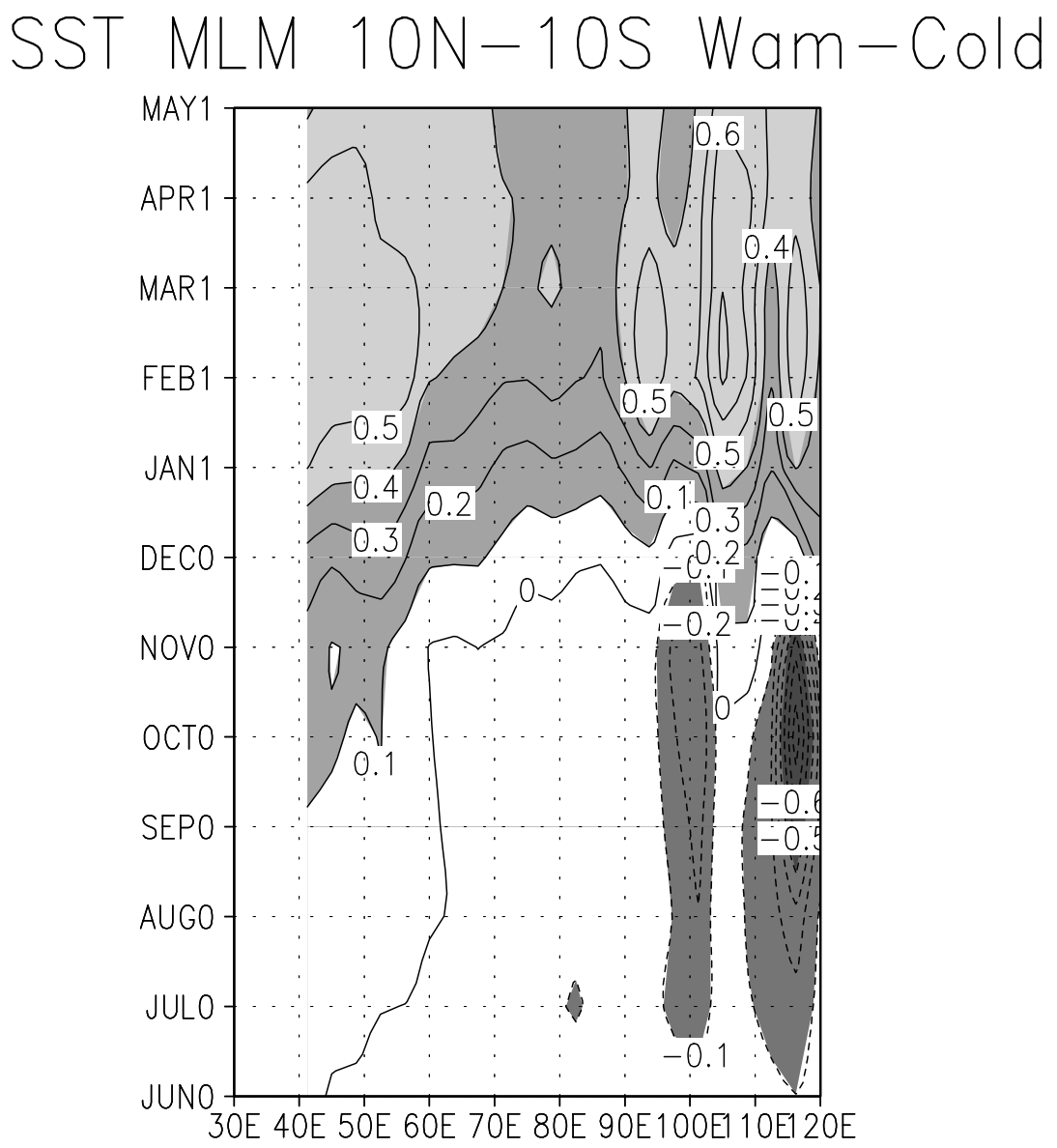

(b)

SST MLM SON Warm-Cold

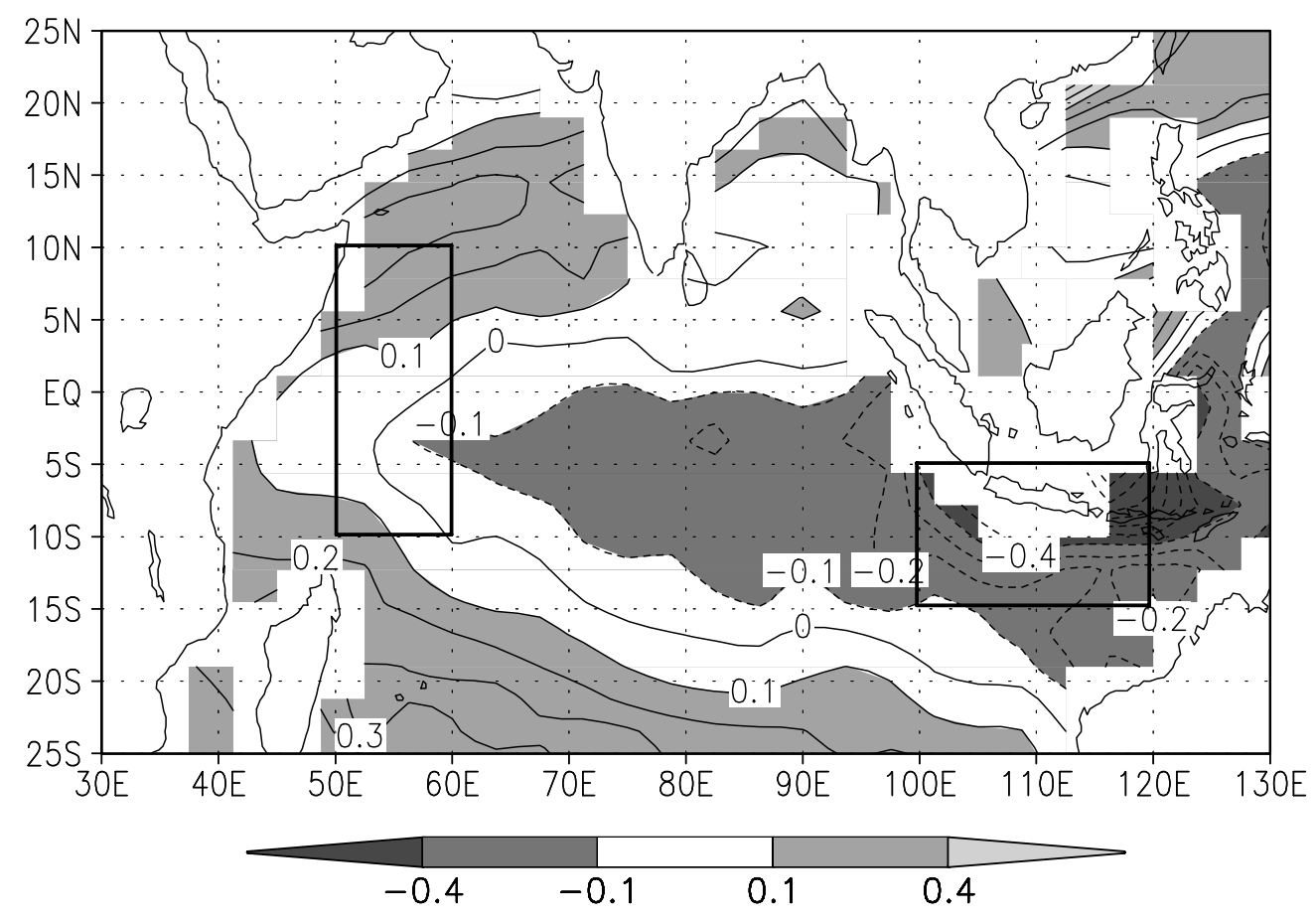


Fig. 12
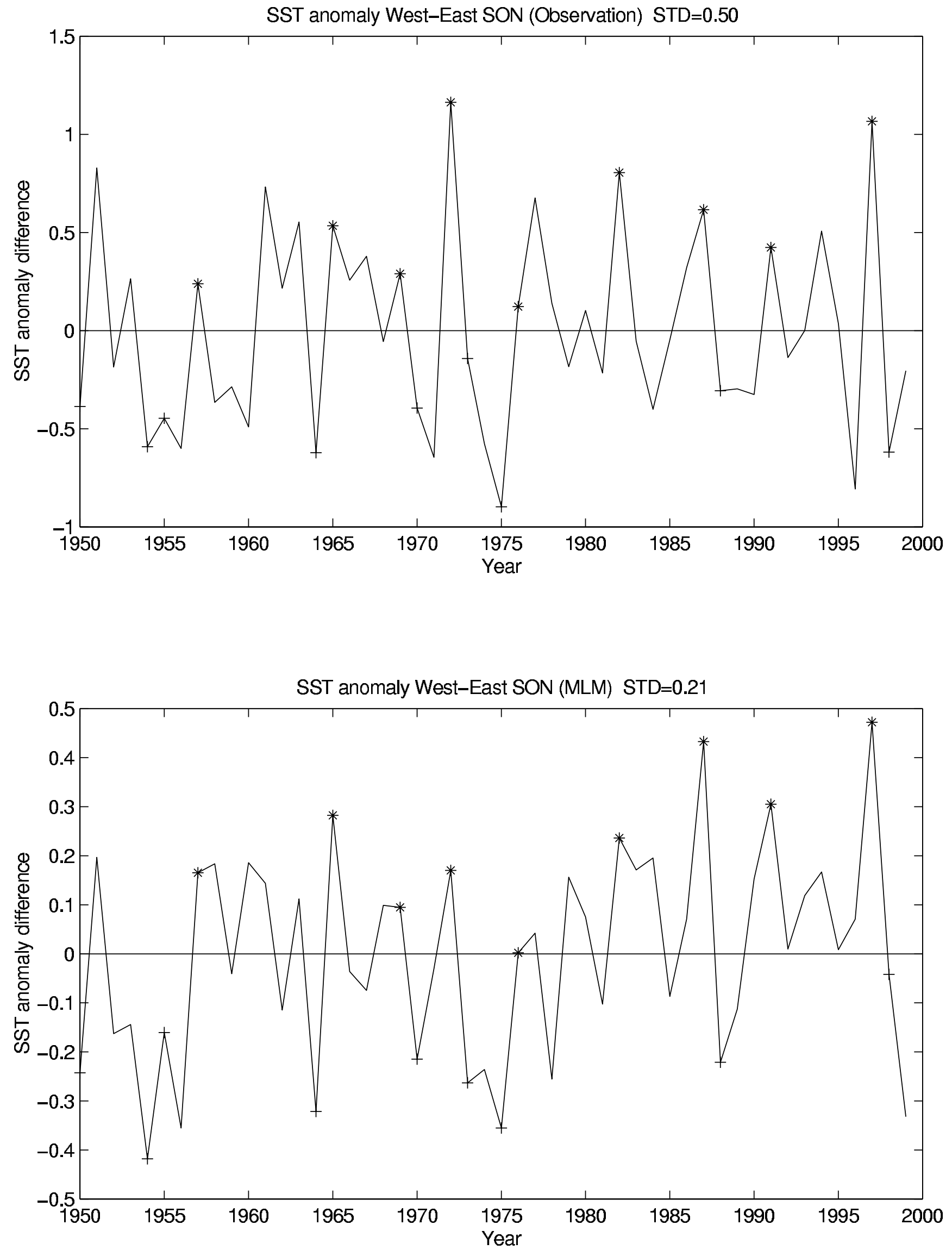